\title{
ORGANIZATIONAL RELATIONSHIP BETWEEN THE SAKHA AGRICULTURAL RESEARCH STATION AND THE AGRICULTURAL EXTENSION ORGANIZATION IN KAFR EL- SHEIKH GOVERNORATE FROM THE VIEWPOINT OF THE MEMBERS OF THE RESEARCH.
}

Abdel Wahab, M.M. E. ; J. I. Issawi and A. A. Ismail

Research Institute of Agricultural Extension and Rural Development Agricultural Research Center.

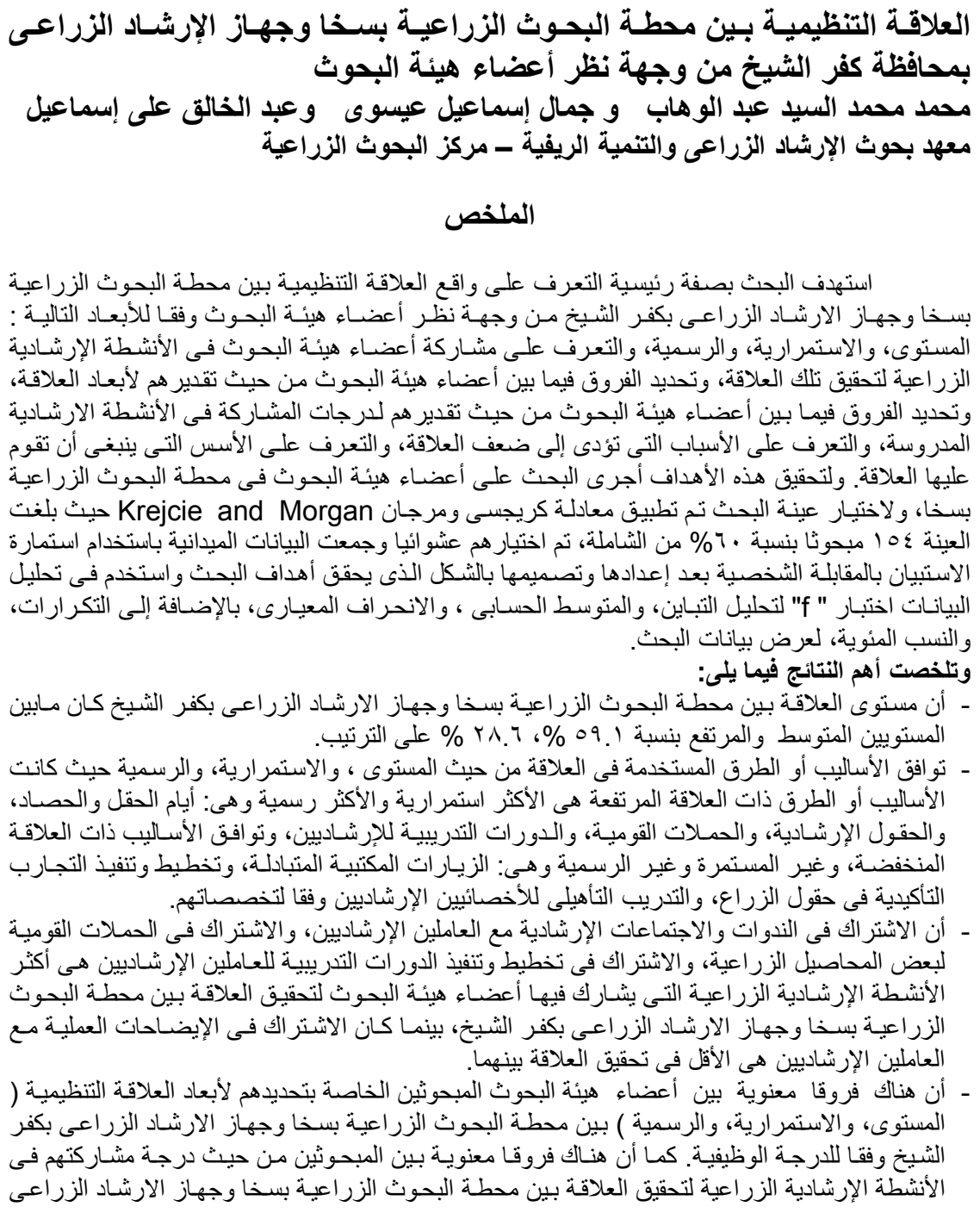


Abdel Wahab, M. M. E. et al.

بكفر الثيخ وفقا للارجة الوظيفية. كما أنه كلما ذادت الدرجة الوظيفية كلما ذاد ادر اكت أعضاء هيئة البحوث

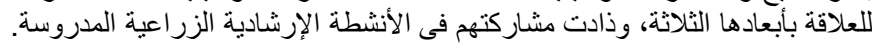

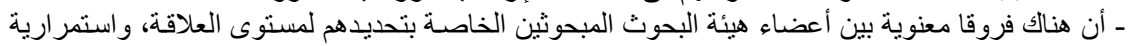

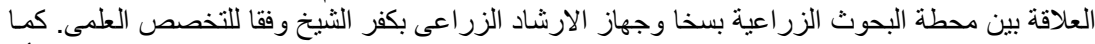

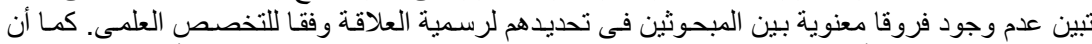

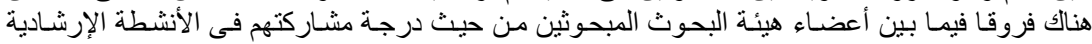

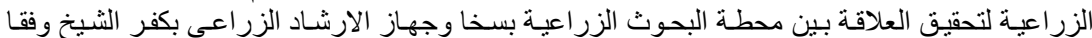

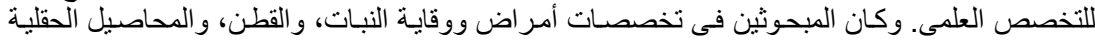

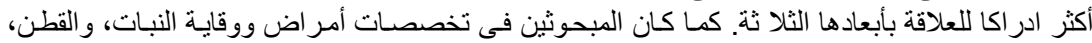

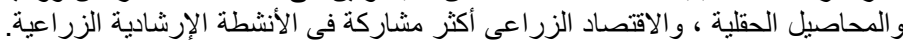

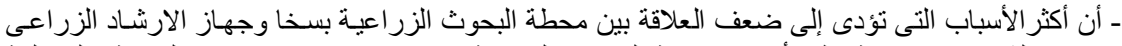

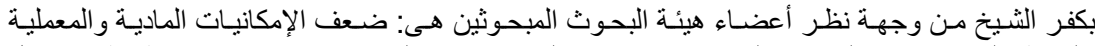

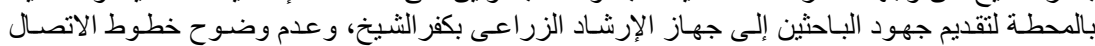

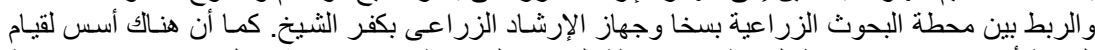

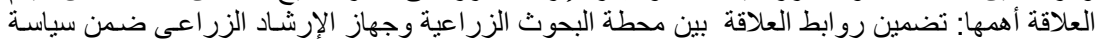

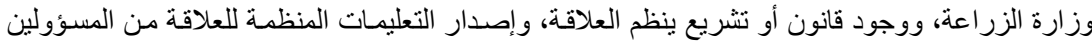
بمركز البحوث الزراعية والإدارة المركزية للإرشاد الزراعى.

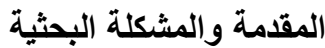

تسعى حكومات الدول النامية إلى إحداث التتميـة الزراعيـة بمـا تنطوى عليهـ من استخدام وتطبيق

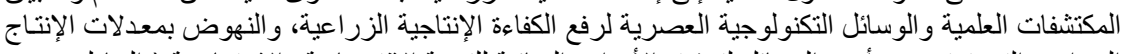

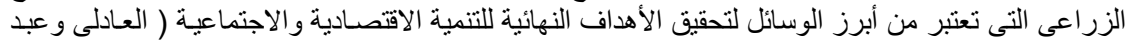

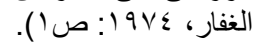

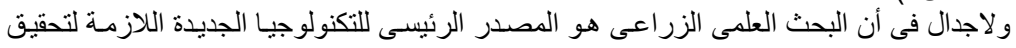

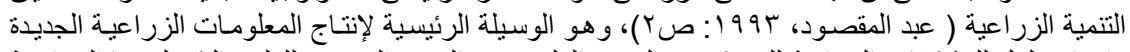

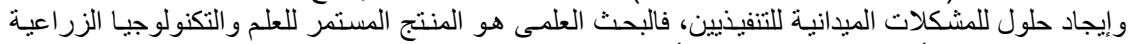

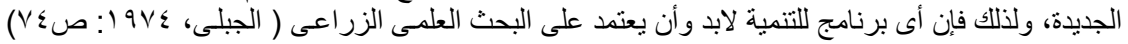

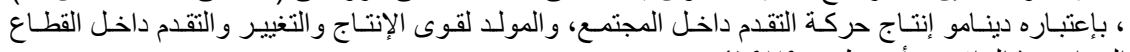

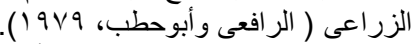

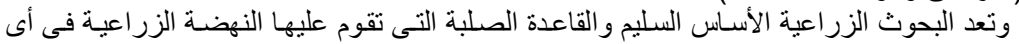

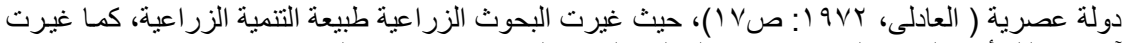

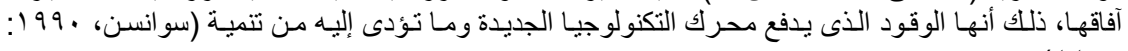

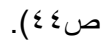

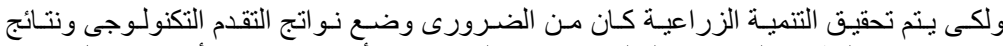

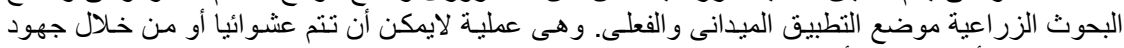

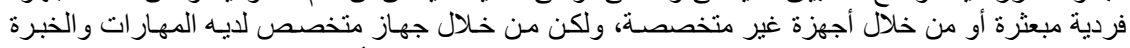

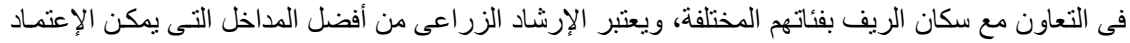

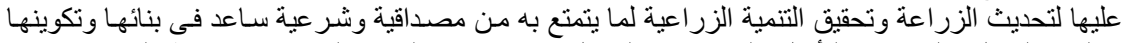

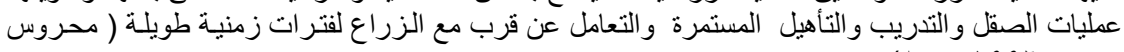

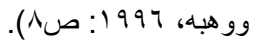

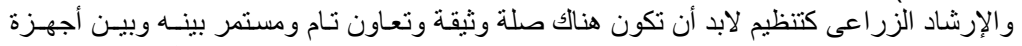

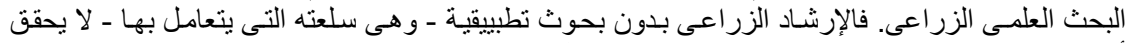

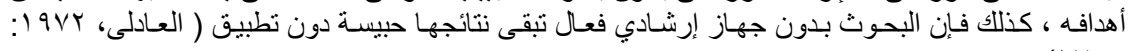

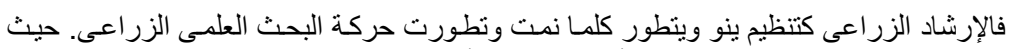

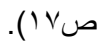
يقوم البحث العلىى باستقصاء الطرق الجديدة والأفضل لعمل الأشياء، بينما يستخدم الإرشاد الزراعى طرق الزرق 
إرشـادية متتوعـة لنقل المستحدثات إلى جمهوره مـن الزراع فلكل وظائفهـ المستقلة، كمـا أن لهما وظائفهـا

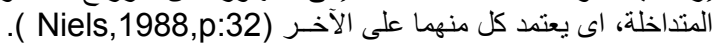

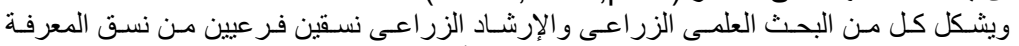

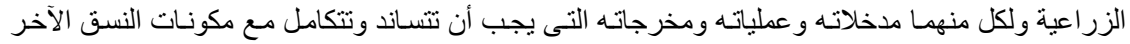

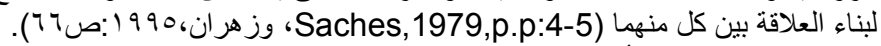

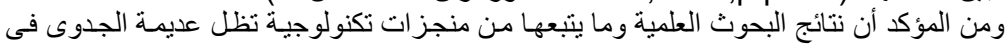

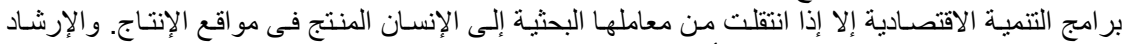

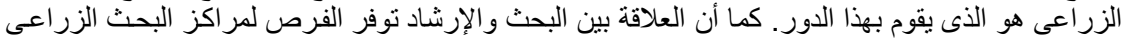

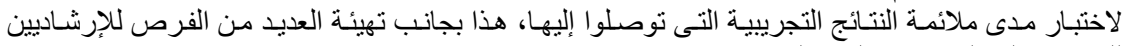

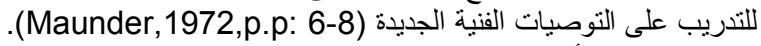

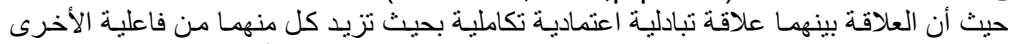

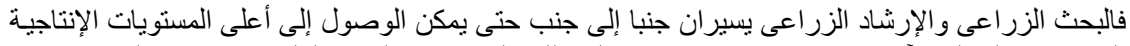

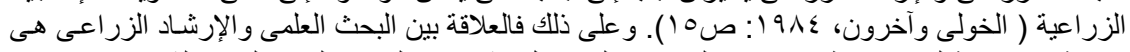

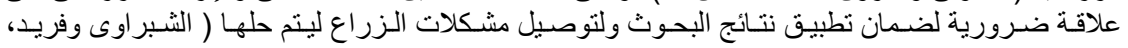

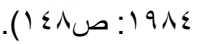

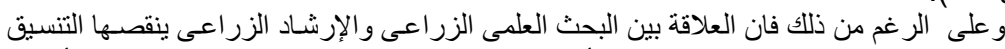

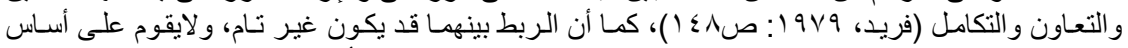

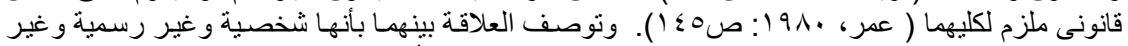

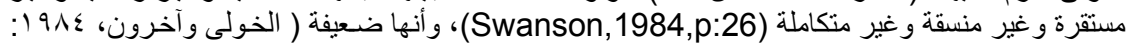

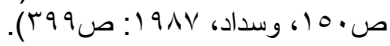

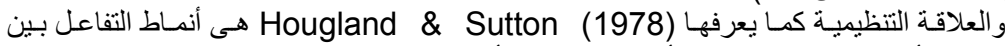

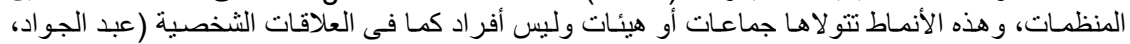

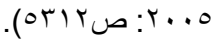

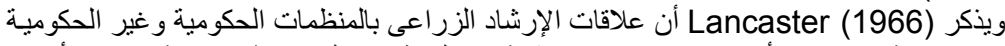

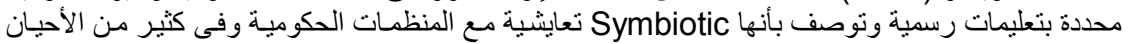

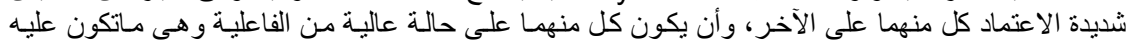

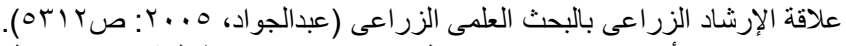

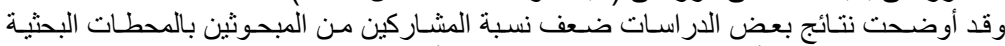

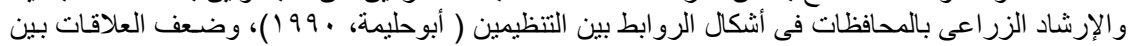

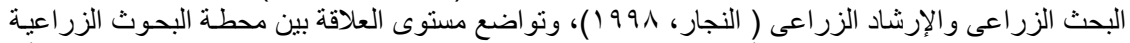

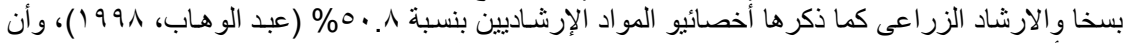

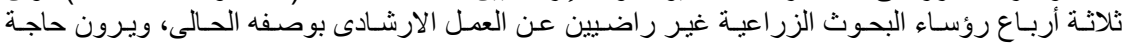

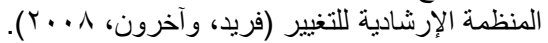

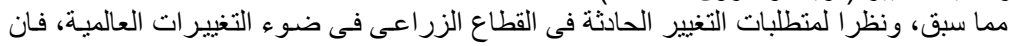

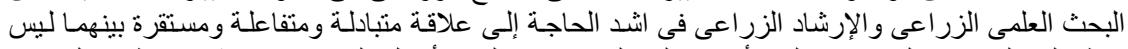

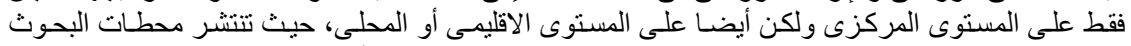

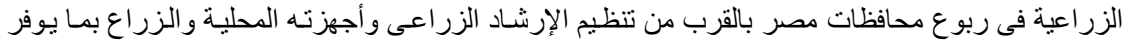

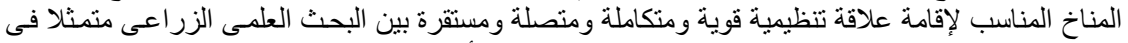

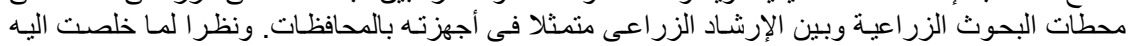

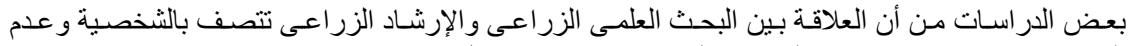

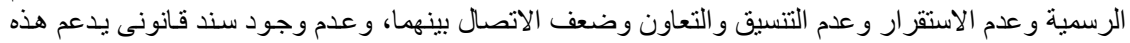

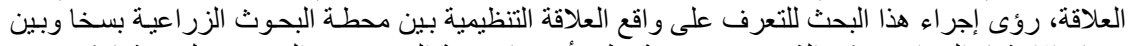

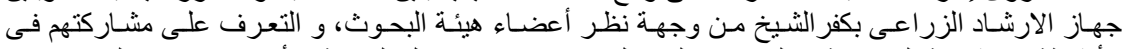

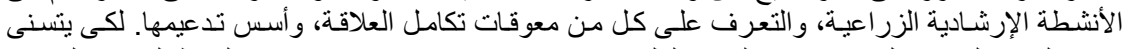

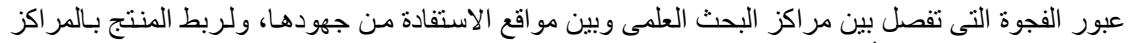

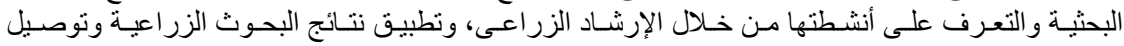

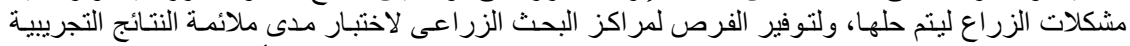

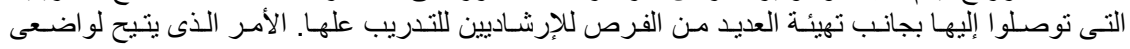


Abdel Wahab, M. M. E. et al.

السياسة الزر اعية تضمين مايسفر عنه البحث من نتائج لتحقيق العلاقـة وزيـادة فاعليتها بين البحث العلمى الزراعى والارشاد الزراعة الخى.

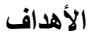

تمشيا مع المشكلة البحثية فقد تم صياغة الأهداف التالية:

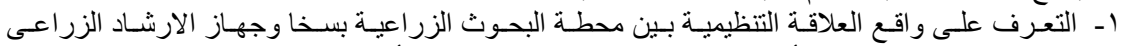

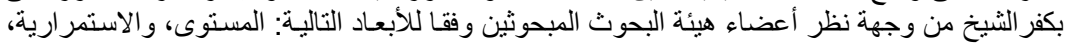
والرسمية. r- التعرف على مشاركة أعضاء هيئة البحوث المبحوثين في الأنشطة الإرشـادية الزر اعيـة لتحقيق العلاقة

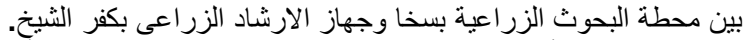

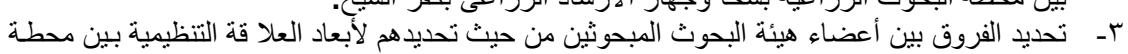

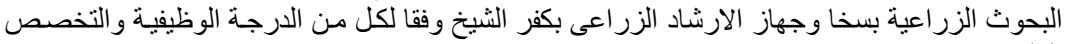
العلمى. ع- - تحديد الفروق بين أعضـاء هيئة البحوث المبحوثين من حيث درجة مشـاركتهم فيى الأنشطة الإرشـادية

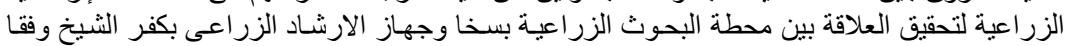

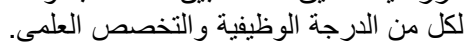

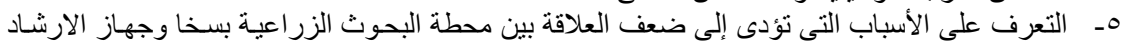

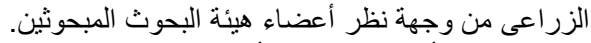

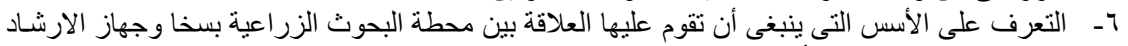
الزراعى من وجهة نظر أعضاء هيئة البحوث المبحوثين.

\section{الفروض البحثية}

لتحقيق هدفى البحث الثالث و الرابع، فقد تمت صياغة الفروض البحت البحتية التالية:

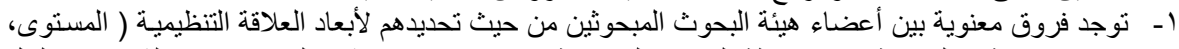

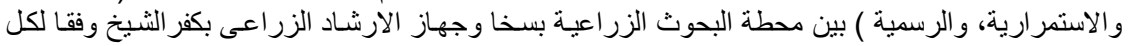

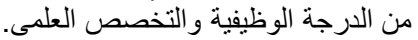

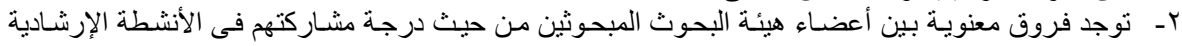

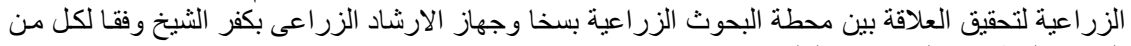

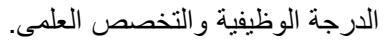

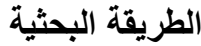

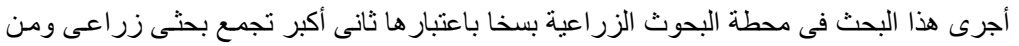

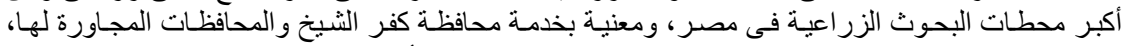

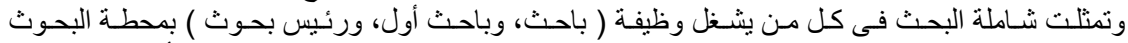

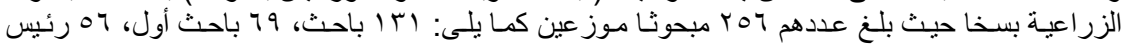

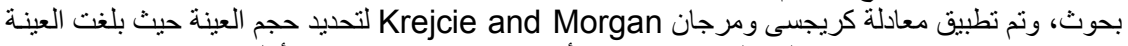

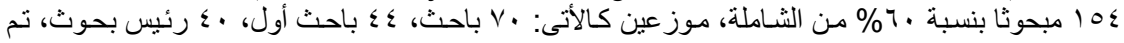

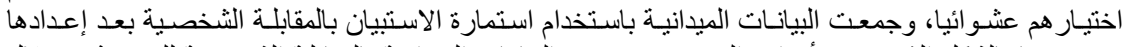

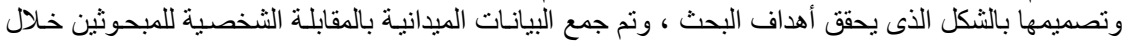

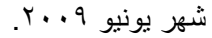
المتغيرات البحثية وقياسها:

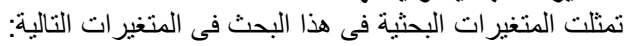

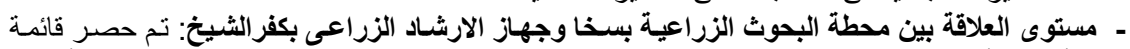

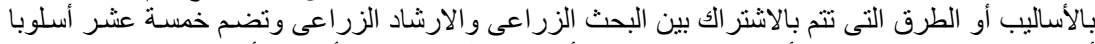

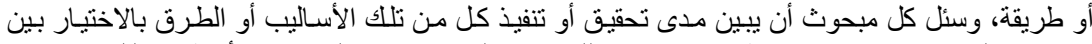

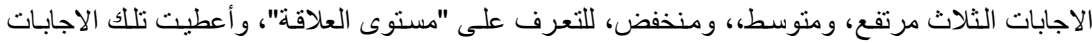

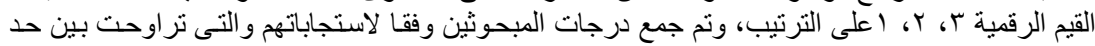




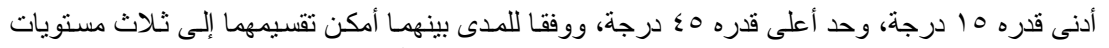

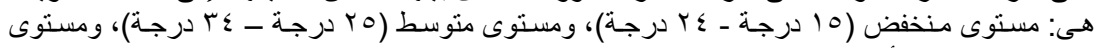

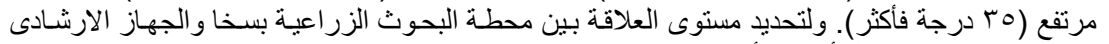

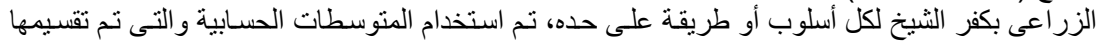

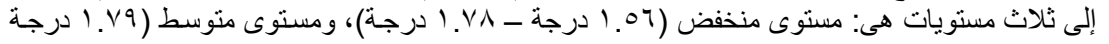

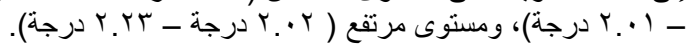

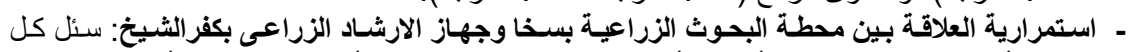

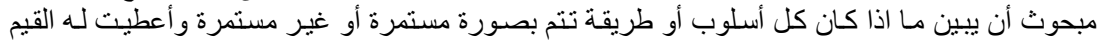

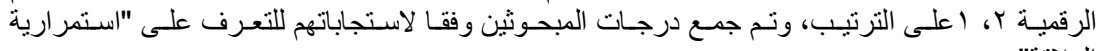

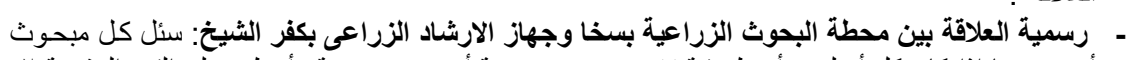

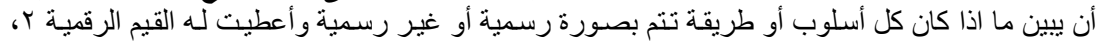

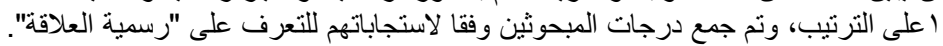

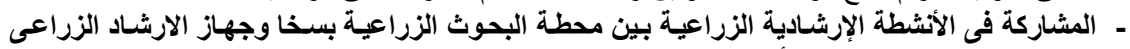

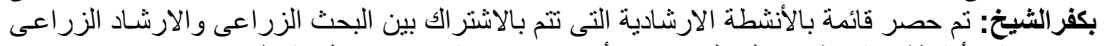

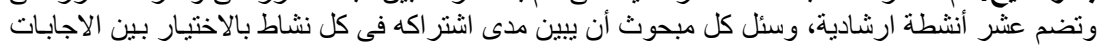

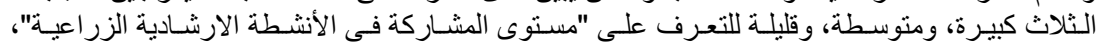

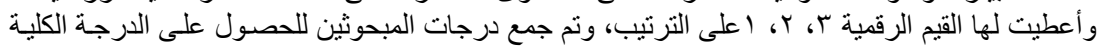

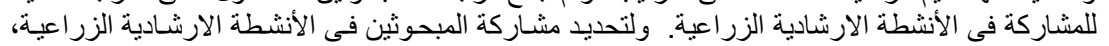

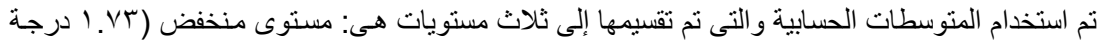

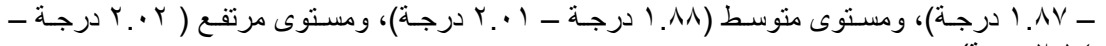

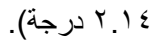

ـ الدرجة الوظيفية: تمثلت فى مسمى الوظائف البحثية (باحث، وباحث أول، ورئ ورئيس بحوث) بمحطة البحوث

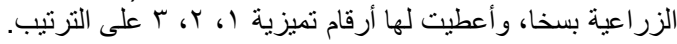

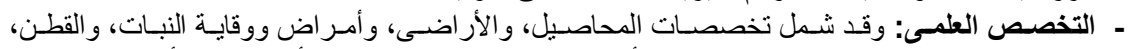

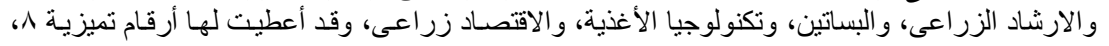

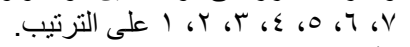

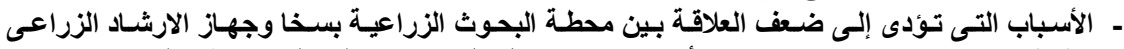

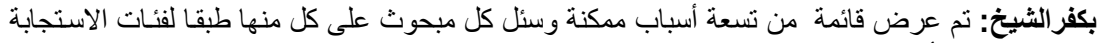

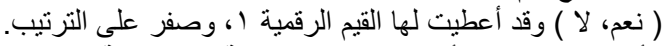

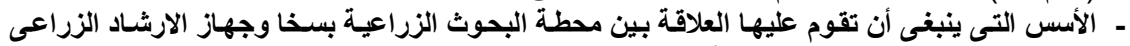

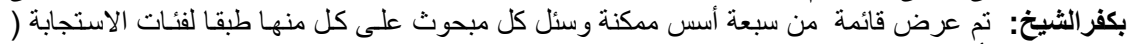

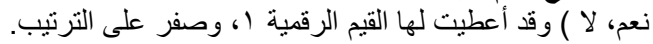

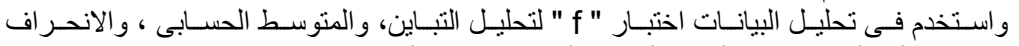

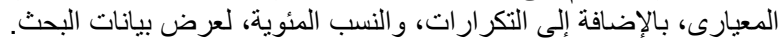

\section{التتائج ومناقشتها}

أولا: واقع العلاقة التظيمية بين محطة البحوث الزراعية بسخا وجهاز الارشاد الزراعى بكفرالشيخ:

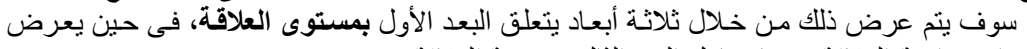

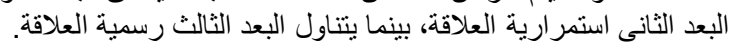

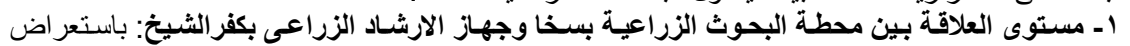

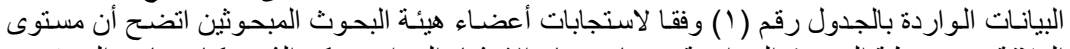

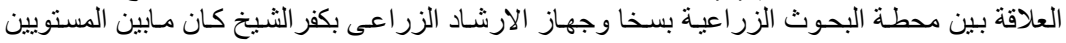

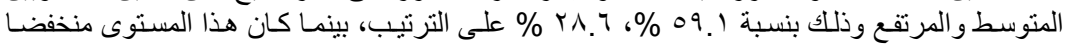

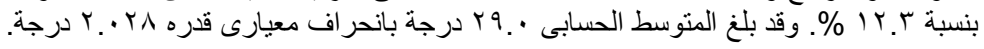


Abdel Wahab, M. M. E. et al.

جدول ( ): التكرارات والنسب المئوية لتوزيع المبحوثين تبعا لمستوى العلاقة بين محطة البحوث الزراعية بسخا وجهاز الارشاد الزراعى بكفر الثيخ لبرئ

\begin{tabular}{|c|c|c|}
\hline$\%$ & عدد & المســـــتـوى \\
\hline TY.r & 19 & مستوى منخفض (10 درجة - ؟ ؟ درجة) \\
\hline 09.1 & 91 & مستوى متوسط (Y0 درجة - ع ب درجة) \\
\hline YA.T & $\varepsilon \varepsilon$ & مستوى مرتفــع (0 ب درجة فأكثر) \\
\hline $1 \cdots$ & $10 \xi$ & الاجمــــــــالى \\
\hline
\end{tabular}

ولمزيد من التفاصيل سوف نعرض مستوى العلاقة بين محطة البحوث الزر اعية بسخا وجهاز

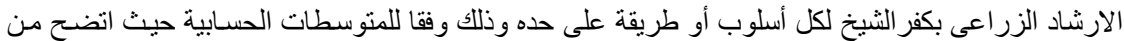

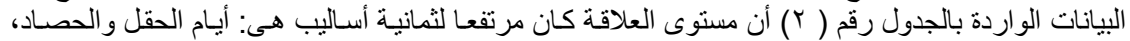

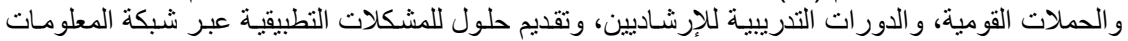

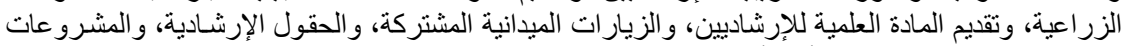

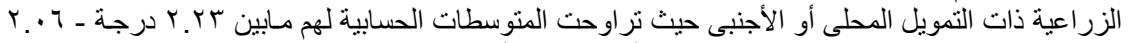

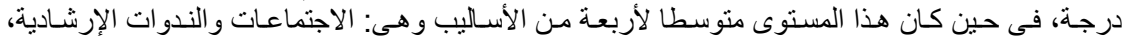

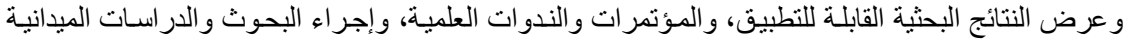

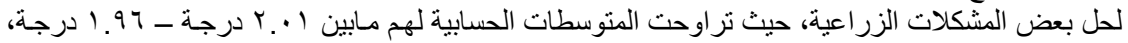

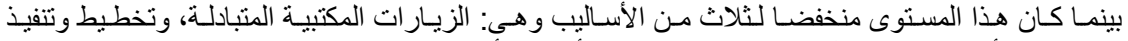

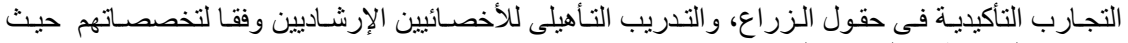

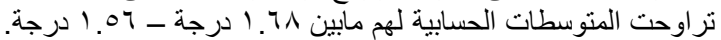

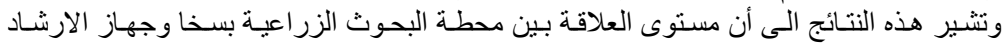

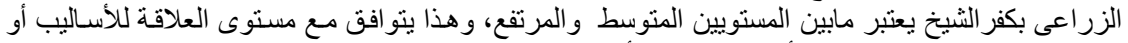

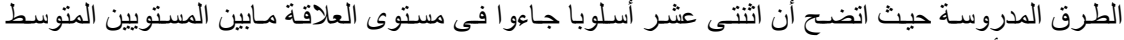

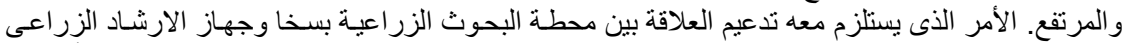

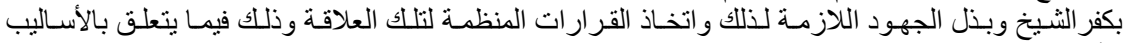
الأخرى المتبقية ذات المستوى المنخفض.

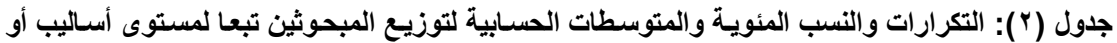
طرق العلاقة بين محطة البحوث الزراعية بسخا وجهاز الارشاد الزئراعى بكفر الثيخ.

\begin{tabular}{|c|c|c|c|c|c|c|c|}
\hline \multirow{2}{*}{ الحستوسطى } & \multicolumn{2}{|c|}{ منخفض } & \multicolumn{2}{|c|}{ متوسط } & \multicolumn{2}{|c|}{ مرتفع } & \multirow{2}{*}{ الأساليب أو الطرق } \\
\hline & $\%$ & عدد & $\%$ & عدد & $\%$ & عدد & \\
\hline$r . \wedge$ & YY.I & $r \varepsilon$ & $\sum \vee . \varepsilon$ & VT & $r \cdot .0$ & $\leqslant V$ & الحقول الإرشادية \\
\hline r.IV & $r \cdot . \Lambda$ & Tr & $\varepsilon 1.7$ & $7 \varepsilon$ & $r V . V$ & $O \Lambda$ & الحملات القومية \\
\hline r.l. & $11 . r$ & $r \wedge$ & or.t & NT & YA. ${ }^{\top}$ & $\varepsilon \varepsilon$ & الزيارات الميدانية المشتركة \\
\hline 1.07 & $0 \leqslant 0$ & $\Lambda \varepsilon$ & ro.1 & $0 \leqslant$ & $1 \cdot . \varepsilon$ & 17 & التذريب التأهيلى للأخصائيين الإرشاديين وفقا لتخصصاتهم. \\
\hline r. $\cdot 1$ & YY." & $\varepsilon$ & $\varepsilon \vee . \varepsilon$ & 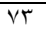 & YY. 7 & $\varepsilon 1$ & الاجتماعات و الندوات الإرشادية \\
\hline Y. $\cdot 7$ & TO.r & rq & $\varepsilon r .0$ & $7 V$ & rI. & $\varepsilon \wedge$ & المشرو عات الزر اعبة ذات التمويل المحلى أو الأجنبى \\
\hline 5.10 & Ir.r & 19 & $7 \cdot . \varepsilon$ & 94 & TV.T & $\varepsilon r$ & الدور ات التدريية للإرشاديين \\
\hline 1.97 & TV.T & $\varepsilon r$ & $\sum 9 . \varepsilon$ & $\sqrt{V 7}$ & Tr. & ru & 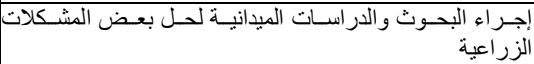 \\
\hline
\end{tabular}




\begin{tabular}{|c|c|c|c|c|c|c|c|}
\hline $1.9 \mathrm{~V}$ & TV.T & $\varepsilon r$ & $\varepsilon \wedge, Y$ & vo & $r \varepsilon$. & $T \mathrm{r}$ & المؤتمر ات و الندو ات العلمية \\
\hline$r .+1$ & $T V^{\prime}, T$ & $\varepsilon r$ & $\varepsilon \leqslant . \wedge$ & 79 & $r v . q$ & $\varepsilon r$ & عرض النتائج البحثية القابلة للتطبيق \\
\hline 1.71 & $\sum 4 . \wedge$ & VY & $r \mu^{r} r$ & 09 & $1 \leqslant .9$ & $T r$ & الزيارات المكتبية المتبادلة \\
\hline 1.77 & $\sum 4.1$ & v) & $\varepsilon r . r$ & 70 & $11 . \mathrm{V}$ & 11 & تخطيط وتنفيذ التجارب التأكيدية في حقول الزراع \\
\hline T.KT & $r \cdot . \Lambda$ & r & ro.y & 00 & $\varepsilon r .0$ & TV & أيام الحقل و الحصاد \\
\hline T.Iई & 19.0 & $r$. & $\varepsilon \vee . \varepsilon$ & $\mathrm{VT}$ & $r+1$ & 01 & تقفيح حلول للمشكلات التطبيقية عبر شبكة المعلومات الزر اعية \\
\hline T.I $\varepsilon$ & 17.9 & $\overline{r q}$ & $0 Y .7$ & A) & $r \cdot .0$ & $\varepsilon v$ & تقديم المادة العلمية للإرشاديين \\
\hline
\end{tabular}

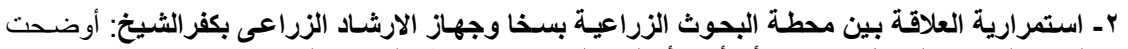

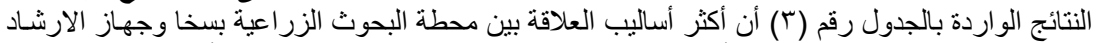

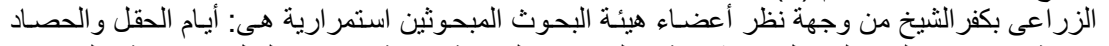

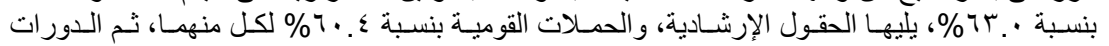

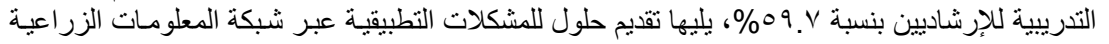

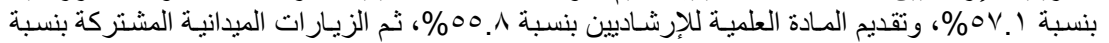

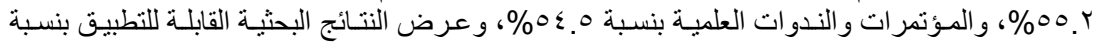

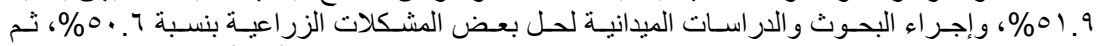

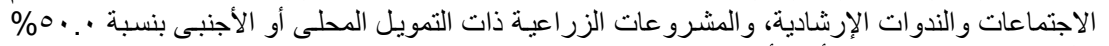

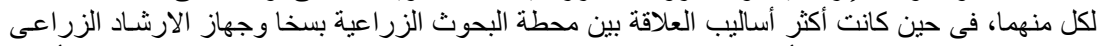

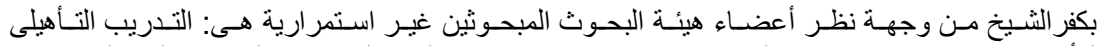

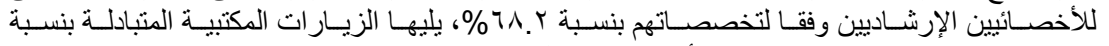

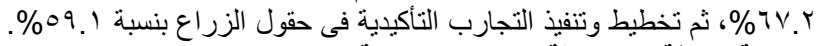

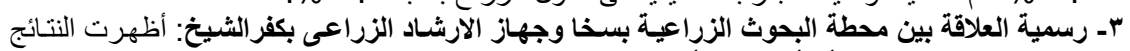

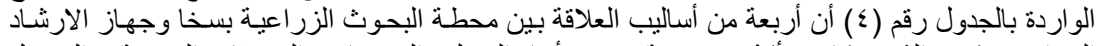

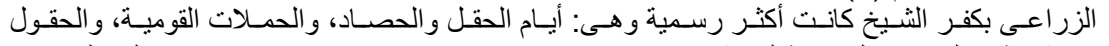

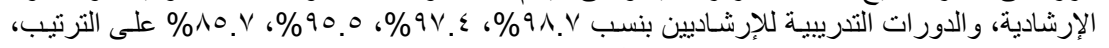

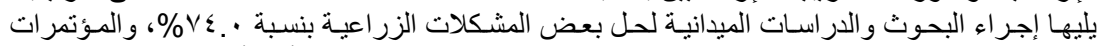

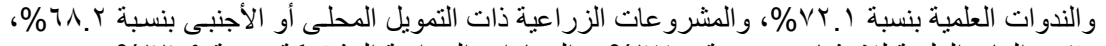

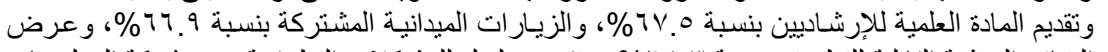

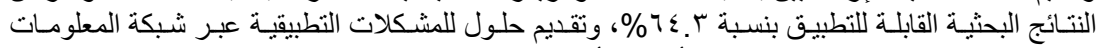

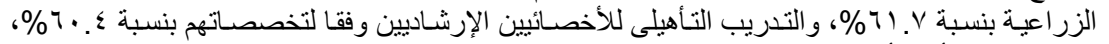

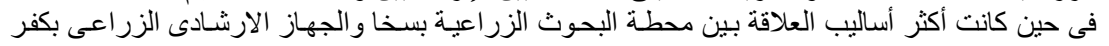

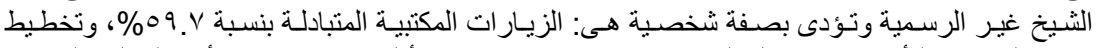

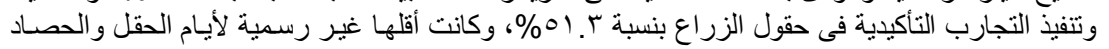

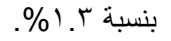

جدول (r): التكرارات والنسب المئويـة لتوزيـع المبحـوثين تبعـا لاستمرارية أسـاليب أو طرق العلاقة بـين

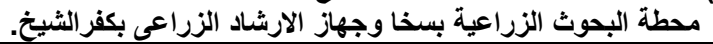

\begin{tabular}{|c|c|c|c|c|}
\hline \multicolumn{2}{|c|}{ غير مستمرة } & \multicolumn{2}{|c|}{ مستمرة } & \multirow[t]{2}{*}{ الأساليب أو الطرق } \\
\hline$\%$ & عدد & $\%$ & عدد & \\
\hline$r 9.7$ & 71 & $7 . \varepsilon$ & 94 & الحقول الإرشادية \\
\hline$r 9.7$ & 71 & $7 \cdot . \varepsilon$ & 94 & الحملات القومية \\
\hline$\varepsilon \leqslant . \wedge$ & 79 & $00 . Y$ & 10 & الزيار ات الميدانية المشتركة \\
\hline $7 \wedge . Y$ & 1.0 & $\Gamma . \Lambda$ & $\leqslant 9$ & التدريب التأهيلى للأخصائيين الإرشاديين وفقا لتخصصاتهم. \\
\hline $0 \cdot$. & VV & $0 . . \cdot$ & VV & الاجتماعات و الندوات الإرشادية \\
\hline $0 .$. & VV & $0 .$. & VV & المشرو عات الزر اعية ذات التمويل المحلى أو الأجنبى \\
\hline$\varepsilon \cdot r$ & T1 & $09 . \mathrm{V}$ & 94 & الدورات التدريبية للإرشاديين \\
\hline ะ१. & $\sqrt{14}$ & $0 . .7$ & $\checkmark \wedge$ & إجر اء البحوث و الدر اسات الميدانية لحل بعض المشكلات الزر اعية \\
\hline$\varepsilon 0.0$ & $\checkmark \cdot$ & $0 \leqslant 0$ & $\Lambda \varepsilon$ & المؤتمرات و الندوات العلمية \\
\hline$\varepsilon \wedge .1$ & $V \varepsilon$ & 01.9 & A. & عرض النتائج البحثية القابلة للنطبيق \\
\hline
\end{tabular}


Abdel Wahab, M. M. E. et al.

\begin{tabular}{|c|c|c|c|c|}
\hline TV.Y & 1.0 & T!. & $\leqslant 9$ & الزيار ات المكتبية المتبادلة \\
\hline 09.1 & 91 & $\varepsilon \cdot .9$ & $4 \pi$ & تخطيط وتنفيذ التجارب التأكيدية فى حقول الزراع \\
\hline$r V_{.}$ & ov & $7 \pi$. & $9 V$ & أيام الحقل و الحصـاد \\
\hline$\varepsilon r . q$ & 77 & ov.1 & AN & تقديم حلول للمشكلات التطبيقية عبر شبكة المعلومات الزراعية \\
\hline$\varepsilon \varepsilon . Y$ & $7 \Lambda$ & 00.1 & 17 & تقديم المادة العلمية للإرشاديين \\
\hline
\end{tabular}

جدول ( ) التكرارات والنسب المئويـة لتوزيع المبحوثين تبعا لرسمية أسـاليب العلاقة بين محطة البحوث

\begin{tabular}{|c|c|c|c|c|}
\hline \multicolumn{2}{|c|}{ غيز رسمية } & \multicolumn{2}{|c|}{ رسمية } & \multirow{2}{*}{ الأساليب أو الطرق } \\
\hline$\%$ & عدد & $\%$ & ع عدد & \\
\hline$\varepsilon .0$ & $\begin{array}{l} \\
\end{array}$ & 90.0 & $1 \leqslant V$ & الحقول الإرشادية \\
\hline r. .7 & $\varepsilon$ & $9 \vee . \varepsilon$ & 10. & 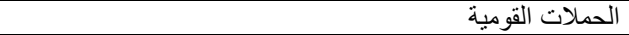 \\
\hline 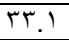 & 01 & 77.9 & 1.4 & الزيار ات الميدانية المشتركة \\
\hline$r 9.7$ & 71 & $7 \cdot .2$ & 94 & التدريب التأهيلى للأخصائيين الإرشاديين وفقا لتخصصاتها. \\
\hline$\varepsilon \varepsilon . Y$ & 71 & 00.1 & $\Lambda 4$ & الاجتماعات و الندوات الإرشادية \\
\hline$r .1$ & $\leqslant 9$ & $7 \Lambda . Y$ & $1 \leqslant$. & المشرو عات الزر اعية ذات التمويل المحلى أو الأجنبى \\
\hline $1 \leq . r$ & rr & 10. $\mathrm{V}$ & ITr & الدورات التدريبية للإرشاديين \\
\hline rч. & $\varepsilon \cdot$ & $V \leqslant . \cdot$ & $11 \varepsilon$ & إجر اء البحوث و الدر اسات الميدانية لحل بعض المشكلات الزر اعية \\
\hline rV.q & $\varepsilon r$ & VY.I & 111 & المؤتمر ات و الندو ات العلمية \\
\hline ro.7 & 00 & $T \leqslant . \Gamma$ & 99 & عرض النتائج البحثية القابلة للتطبيق \\
\hline $09 . \mathrm{V}$ & 94 & $\varepsilon \cdot r$ & TY & الزيار ات المكتبية المتبادلة \\
\hline $01 . r$ & v9 & $\varepsilon \wedge . \vee$ & Vo & تخطيط وتنفيذ التجارب التأكيدية فى حقول الزراع \\
\hline $1 . r$ & $r$ & $91 . \mathrm{V}$ & $10 Y$ & أبام الحقل و الحصاد \\
\hline rᄉ.r & 09 & $71 . \mathrm{V}$ & 90 & تقديم حلول للمشكلات التطبيقية عبر شبكة المعلومات الزر اعية \\
\hline Tr.o & 0. & $T V .0$ & $1 \cdot \varepsilon$ & تقديم المادة العلمية للإرشاديين \\
\hline
\end{tabular}

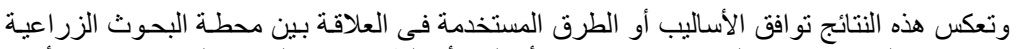

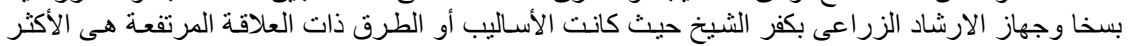

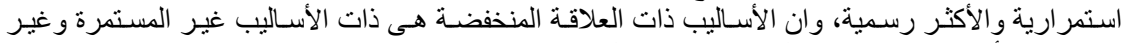

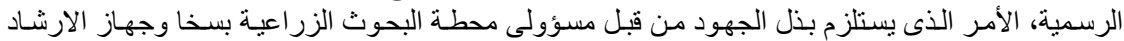

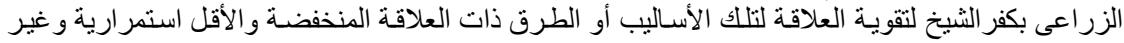

الرسمية.

ثانيا: مشاركة أعضـاء هيئة البحوث المبحوثين في الأنشطة الإرشـادية الزراعية لتحقيق العلاقة بين محطة

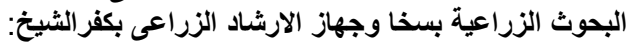

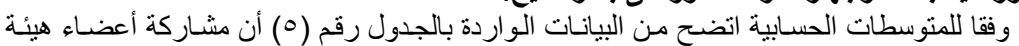

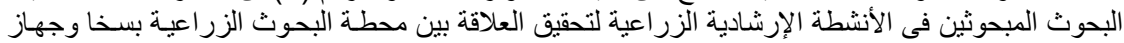

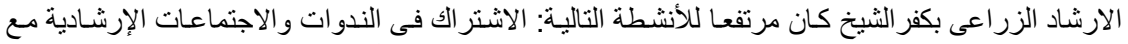

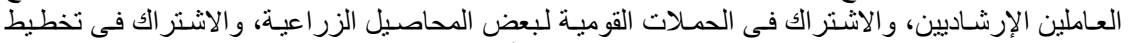

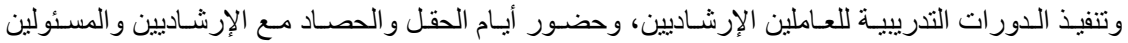

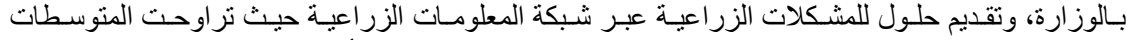

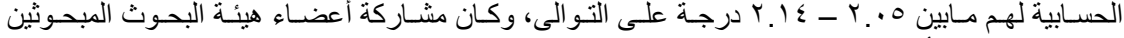

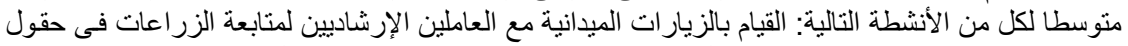

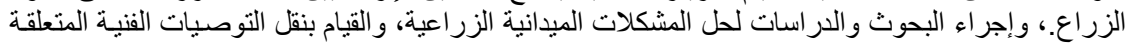

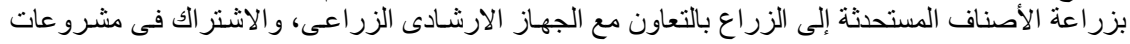

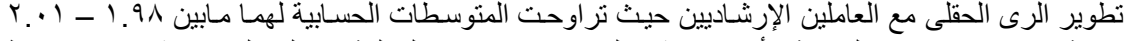

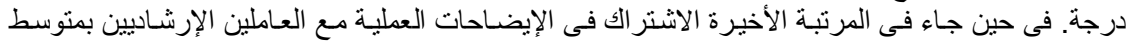

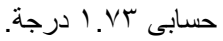




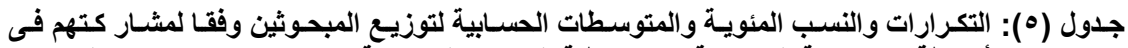

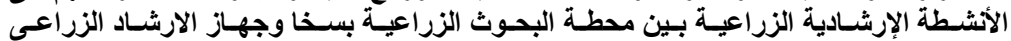

\begin{tabular}{|c|c|c|c|c|c|c|c|}
\hline \multirow{2}{*}{ الحستوسط } & \multicolumn{2}{|c|}{ منذفض } & \multicolumn{2}{|c|}{ متوسط } & \multicolumn{2}{|c|}{ مرتفع } & الأتشطة الارشادية \\
\hline & $\%$ & عدد & $\%$ & عدد & $\%$ & عدد & \\
\hline r.Ir & $1 \wedge . \wedge$ & rq & 0.7 & VA & $r \cdot .0$ & $\leqslant v$ & الز الاشتية. اك فى الحملات القومية لبعض المحاصيل \\
\hline$r .97$ & TY.Y & ro & 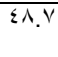 & vo & YA.T & $\varepsilon \varepsilon$ & 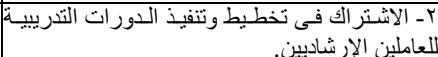 \\
\hline $1 . V \%$ & $\{0,0$ & v. & $r 4 . \varepsilon$ & 04 & IN.Y & YA & 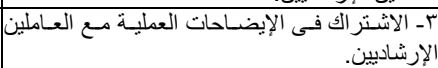 \\
\hline T.I $\varepsilon$ & IV.O & rV & 0.7 & VA & $\Gamma, \Lambda$ & $\leqslant 9$ & العاملين الإرشاديين. الندوات والاجتماعات الإرشادية مح \\
\hline$r . \cdot 1$ & Tr.\& & $r 4$ & or. 4 & N1 & $r \xi$. & rv & لمتابعة الزيام بالزيات في حقوات الميدانة مع العاملين الإرشـاديين \\
\hline 5.0 & Tr. & ry & $\varepsilon \wedge, V$ & vo & TV.q & $\varepsilon r$ & و المسئولين بــور أيسام الحقـل وارة. \\
\hline$r .$. & $r 9.9$ & $\leqslant 4$ & $\varepsilon \cdot r$ & Tr & $r 9.9$ & $\leqslant 4$ & لالميدانية الزراء البحوثة والدراسات لحل المشكلات \\
\hline$r .{ }^{\top} r$ & r४. & $\varepsilon$ & $\varepsilon \varepsilon . \wedge$ & 79 & rq.Y & «o & 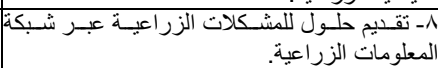 \\
\hline 1.91 & TO.r & rq & 01.5 & 19 & $T V . \varepsilon$ & $r 4$ & 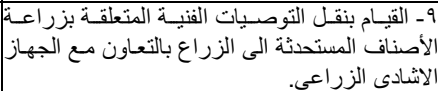 \\
\hline $1.9 \varepsilon$ & $r q .1$ & $\varepsilon_{0}$ & «4.1 & vi & TE.. & rv & 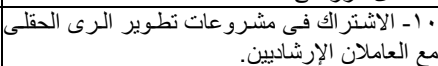 \\
\hline
\end{tabular}

ثالثا: الفروق بين أعضاء هيئة البحوث المبحوثين من حيث تحديدهم لأبعاد العلاقة التظظيمية بين محطة

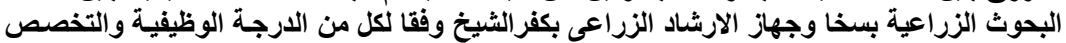

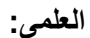

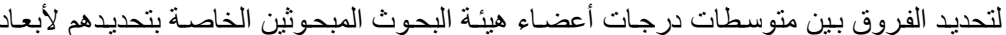

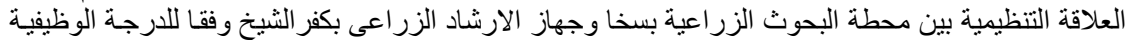

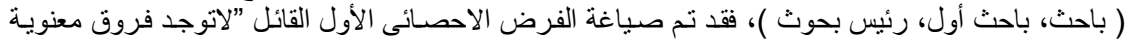

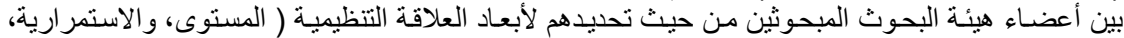

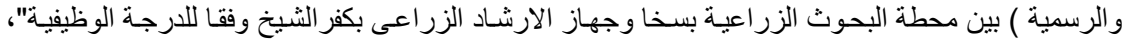

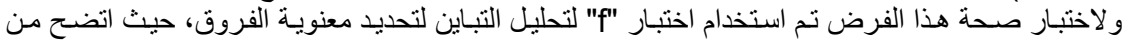

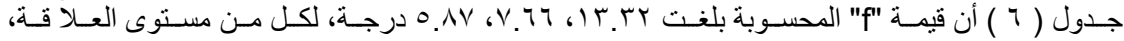

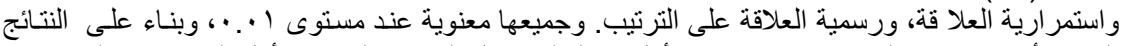

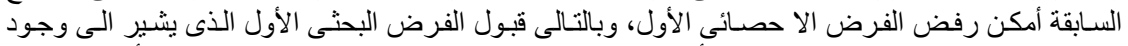

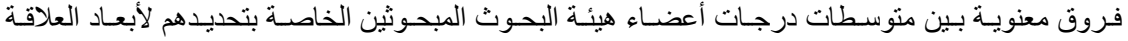

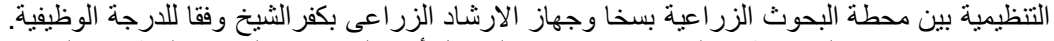

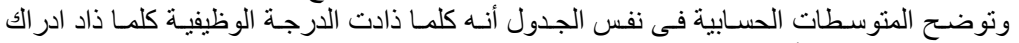

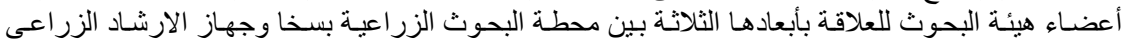
بكفر الثيخ.

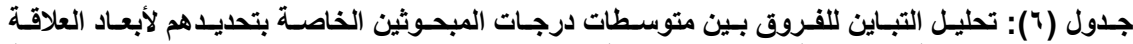

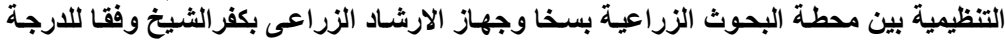

الوظيفية.

\begin{tabular}{|c|c|c|c|c|c|c|c|c|}
\hline قيمة"f " ق " & التباين & الرجاتة & مجموع مربع & مصدر التباين & الالانحراف & المسابي & كيفية & |الأبعاد المدروسة \\
\hline$* * 1$ & $\begin{array}{l}\xi 17.9 \\
r 1 \%\end{array}$ & $\begin{array}{l}Y \\
101\end{array}$ & $\begin{array}{l}\text { Nrr.q } \\
\text { svro! }\end{array}$ & إدبين الدجمو عاتات & $\begin{array}{l}0 . \wedge 1 \\
\varepsilon \hat{y}, r\end{array}$ & $\begin{array}{l}r Y Y \\
r . Y\end{array}$ & لياحثث أور & مستوى العلاقة \\
\hline
\end{tabular}


Abdel Wahab, M. M. E. et al.

\begin{tabular}{|c|c|c|c|c|c|c|c|c|}
\hline & & 104 & 0009.0 & |المجموع & 0.90 & Tr.o & رئيس بحوث & \\
\hline \multirow[t]{3}{*}{$* * Y .77$} & $1 \leq 0 . Y$ & $r$ & $r q . . r$ & |بين المجمو عات & T.V. & rI.r & 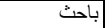 & \multirow{3}{*}{ العلاقة لـتمر ارية } \\
\hline & 11.9 & 101 & r109.1 & |داخل المجموعات & $\leqslant . \wedge 1$ & rT. T & باحث أول & \\
\hline & & 104 & $r 10 . .1$ & المجموع & $\leqslant .77$ & $r \leq .7$ & رئيس بحوث & \\
\hline \multirow[t]{3}{*}{$* * 0, \wedge V$} & 1.8 .7 & $r$ & rlo.r & بين المجمو عات & r.v. & Tr. & باحث & \multirow[t]{3}{*}{ رسمية العلاقة } \\
\hline & $11 . r$ & 101 & rVฯะ.) & داخـــل المجمو عـــات & $\varepsilon . V \varepsilon$ & ro.r & باحث أول & \\
\hline & & 104 & rqva.r & | المجموع & โ.TV & r..1 & رئيس بحوث & \\
\hline
\end{tabular}

لتحديد الفروق بين متوسطات درجات أعضاء هيئة البحوث المبحوثين الخاصة بتحديدهم لأبعاد

ץ. التخصص العلمى:

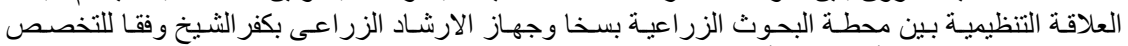

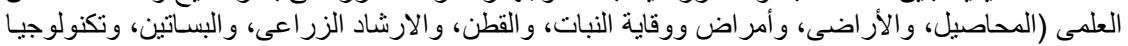

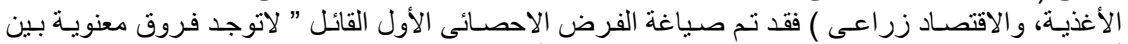

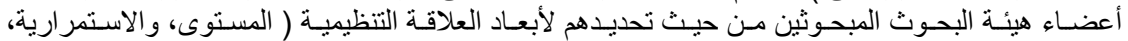

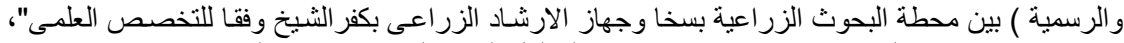

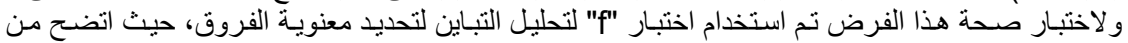

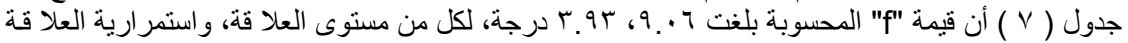

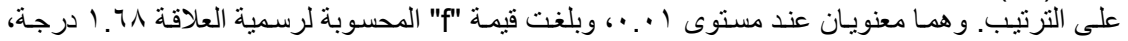

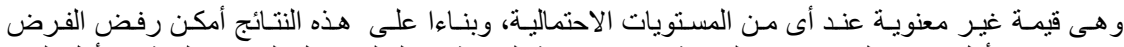

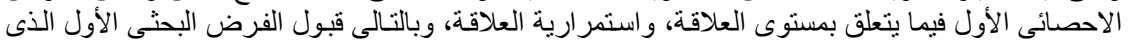

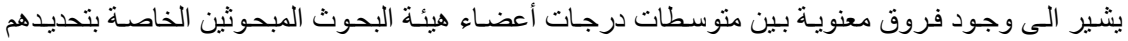

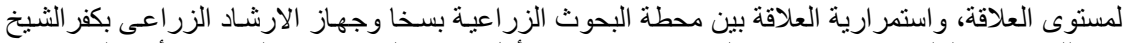

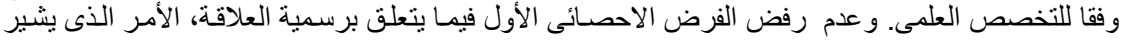

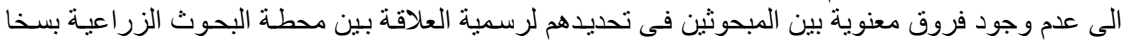

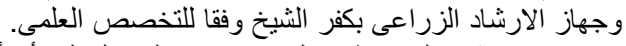

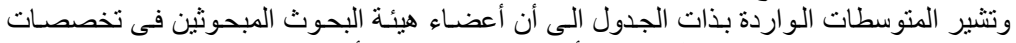

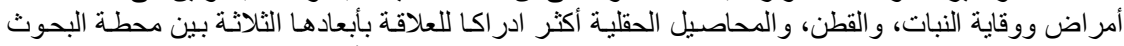

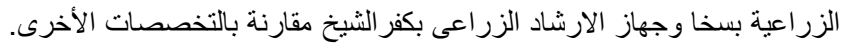

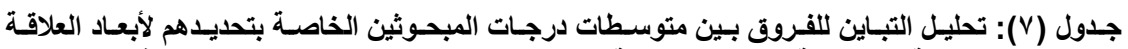

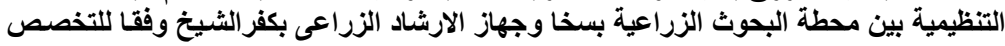

\begin{tabular}{|c|c|c|c|c|c|c|c|c|}
\hline \\
\hline " قيمة" f & التباين & الحرجية & مجمرع مريع & مصدر التباين & المعيارى & الحسابى & التخصص العلمى & 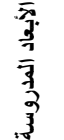 \\
\hline$* * 9.9$ & $\begin{array}{l}r \varepsilon, T^{\prime} \\
r \uparrow .0\end{array}$ & $\begin{array}{l}V \\
1 \leqslant 7 \\
104\end{array}$ & $\begin{array}{l}\text { lTAs.r } \\
\text { rAvo.r } \\
0009.0\end{array}$ & بالخل المجموع عات & 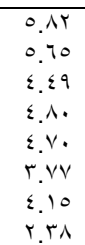 & $\begin{array}{l}r r .7 \\
r A . r \\
r o .9 \\
r \varepsilon . \varepsilon \\
r q .1 \\
r A . r \\
r y . \\
r . .0\end{array}$ & 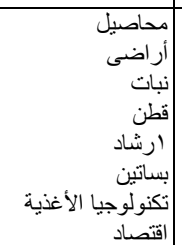 & 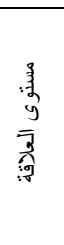 \\
\hline$k * ץ .9 \Gamma$ & $\begin{array}{l}V \backslash . \varepsilon \\
\mid A .1\end{array}$ & $\begin{array}{l}r \\
1 \leq 4 \\
104\end{array}$ & $\begin{array}{l}0 \ldots .9 \\
r 70 \% \\
r 10 .\end{array}$ & داخل المجمو عات & 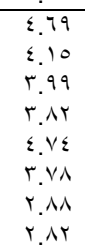 & $\begin{array}{l}r y .7 \\
r r . r \\
r o . r \\
r o .1 \\
r y .9 \\
r r . r \\
r .9 \\
r o . \\
r y\end{array}$ & 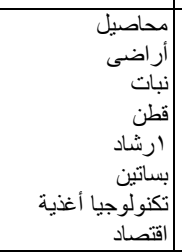 & $\begin{array}{l}\frac{\overline{3}}{3} \\
\frac{3}{3} \\
\frac{3}{3} \\
\frac{3}{9}\end{array}$ \\
\hline
\end{tabular}




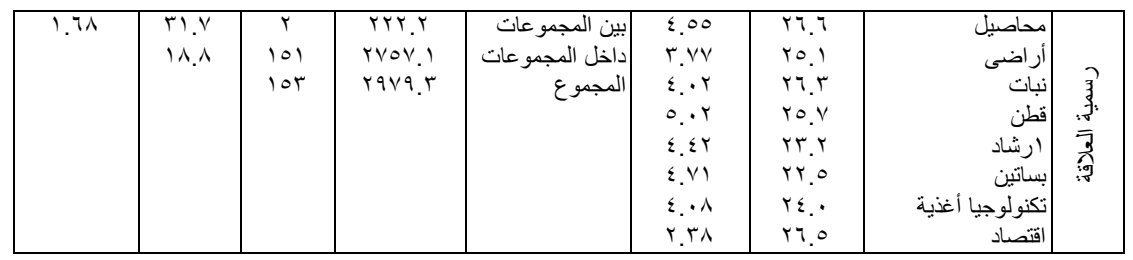

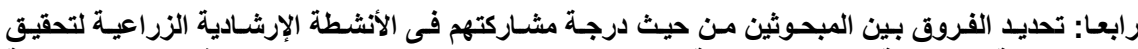

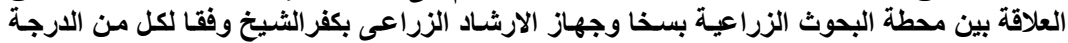

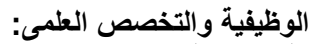

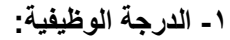

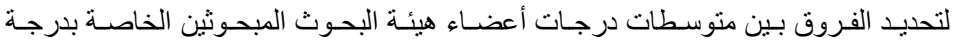

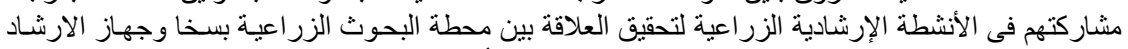

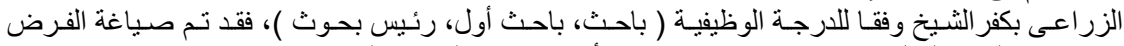

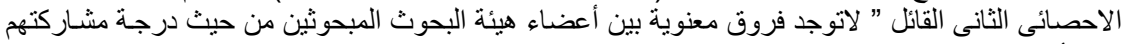

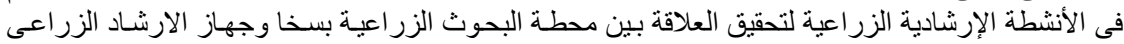

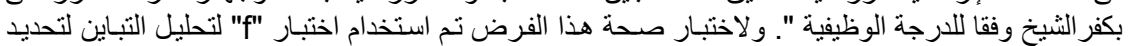

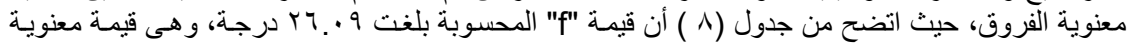

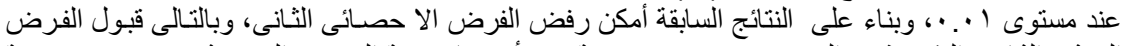

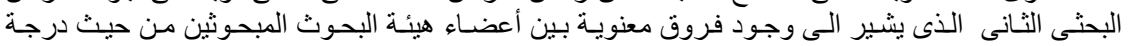

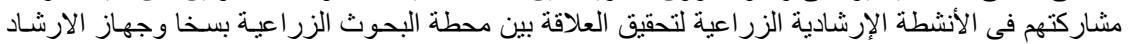
الزراعى بكفر الثيخ وفقا للارجة الوظية الزيفية.

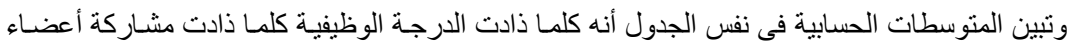

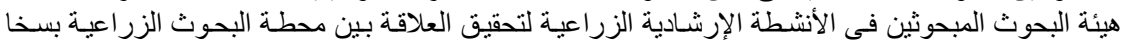
وجهاز الارشاد الزراعى بكفر الثيخ.

جـول (^): تحليـل التبـاين للفـروق بـين متوسـطات درجـات مشــاركة المبــوثين فـى الأشـطة الا رشـادية

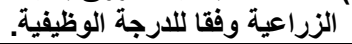

\begin{tabular}{|c|c|c|c|c|c|c|c|c|}
\hline "f" قيمة & التباين & الحرية & الانمر افات مربع & مصدر التباين & الالتحراف & الحستوسط & الوظيفية & المتغير \\
\hline \multirow[t]{3}{*}{$\overline{* * Y ५ .99}$} & or.. & $r$ & $1 \cdot 9 \cdot . r$ & بيين المجمو عات & $0 . r 4$ & 17.7 & 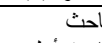 & المشـارك \\
\hline & $r \cdot . r$ & 101 & r.TV.r & داخل المجموعات & r.vo & $r \cdot r$ & & الأنثــــا \\
\hline & & 104 & $\varepsilon \mid r V .0$ & |المجلموع & 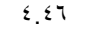 & $r \varepsilon . \cdot V$ & ئيس بحوث & الارشادية \\
\hline
\end{tabular}

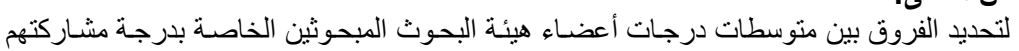

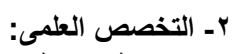

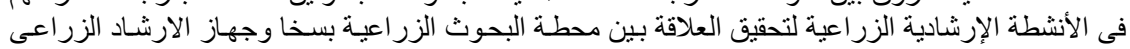

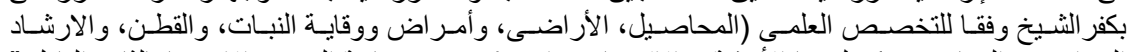

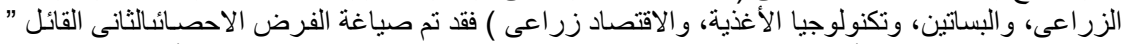

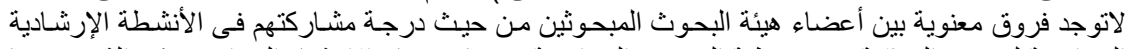

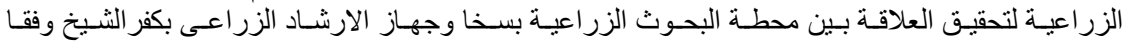

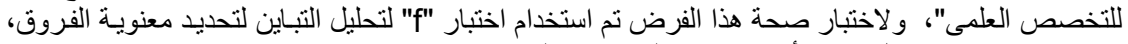

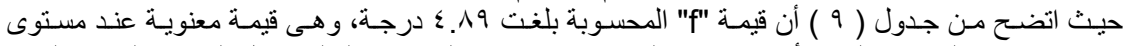

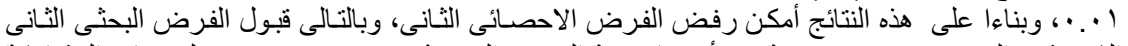

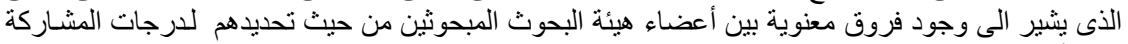

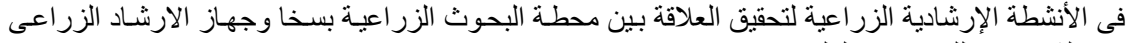

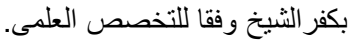


Abdel Wahab, M. M. E. et al.

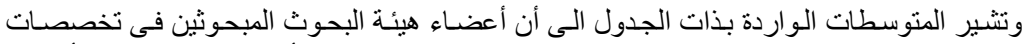

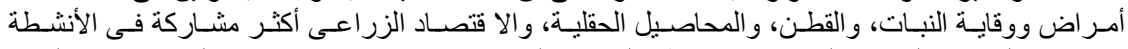

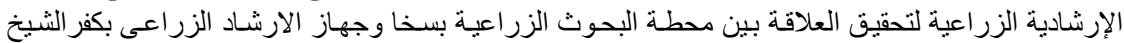
مقارنة بالتخصصات الأخرى.

جدول (9): تحليـل التبـاين للفـروق بين متوسـات درجـات مشـاركة المبحـوثين فـى الأنثـة الار شـادية

\begin{tabular}{|c|c|c|c|c|c|c|c|c|}
\hline " قيمة "f & التباين & الدرجية & |لانحمرع افات & مصدر التباين & |الالحعراف & الحستوسط | الحسب & التخصص العلمى & المتغير \\
\hline$* * \varepsilon, \wedge q$ & $\begin{array}{l}M r .1 \\
r r . \wedge\end{array}$ & $\begin{array}{l}V \\
1 \leq 7 \\
104\end{array}$ & $\begin{array}{l}\text { YAO.1 } \\
\text { rrEY. } \\
\text { sIrV.0 }\end{array}$ & الدجل المجموع عات & $\begin{array}{l}0 . . \\
\varepsilon .0 \leqslant \\
\varepsilon .00 \\
\varepsilon . r 4 \\
0.9 \\
r .74 \\
Y .91 \\
0.14\end{array}$ & 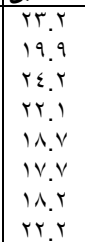 & أنبات أراضى & 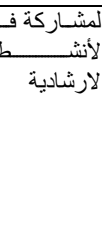 \\
\hline
\end{tabular}

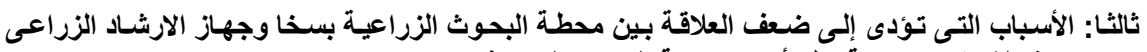
بكفر الثيخ من وجهة نظر أعضاء هيئة البحوث المبحوثة البحثين:

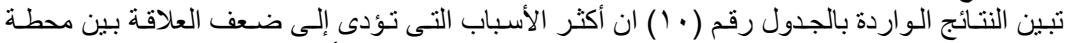

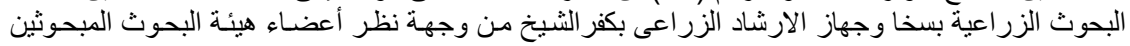

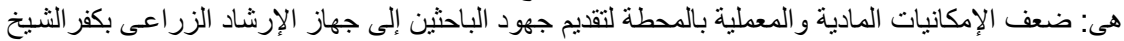

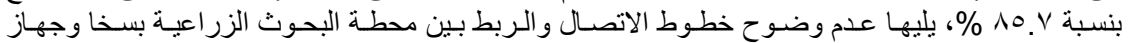

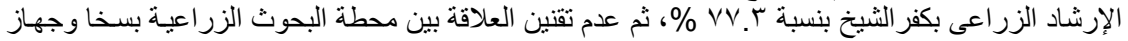

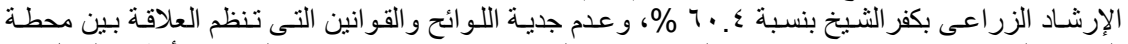

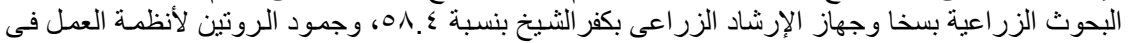

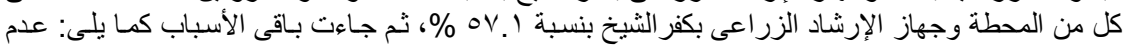

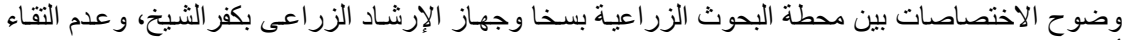

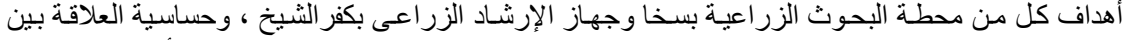

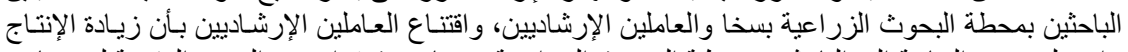

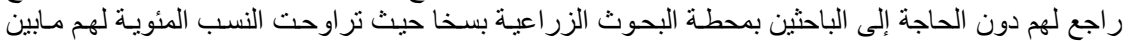

$\% \leqslant r .0-\% 17.9$

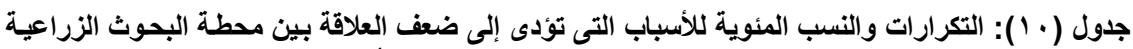

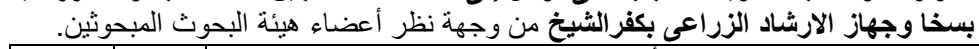

\begin{tabular}{|c|c|c|c|}
\hline$\%$ & عدد & الأسباب & \\
\hline VY.T & 119 & 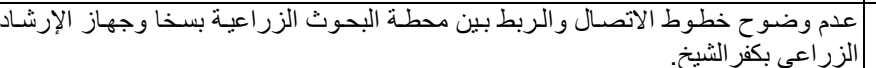 & 1 \\
\hline$\varepsilon r .0$ & TV & |بكفر الثشيخ. وضوح الاختصاصـات بين محطـة البحوث الزر اعيـة بسخا وجهاز الإرشـاد الزراعى & r \\
\hline$r v$. & or & |الإرشاد الزر اعى.بكفر الثشيخ. & r \\
\hline $7 . \varepsilon$ & 94 & عدم تقنين العلاقة بين محطة البحوث الزر اعية بسخا وجهاز الإرشاد الزر اعى.بكفر الثيخ. & $\varepsilon$ \\
\hline 17.9 & Y & |اقتتناع العاملين الإرشاديين بأن زيادة الإنتاج راجع لهم دون الحاجة إلى الباحثين بالمحطة. & 0 \\
\hline $0 \Lambda . \varepsilon$ & 9. & 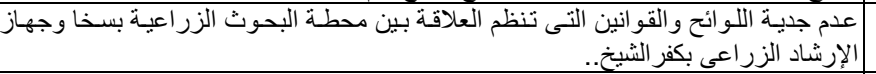 & 7 \\
\hline 0.1 & $\Lambda \Lambda$ & 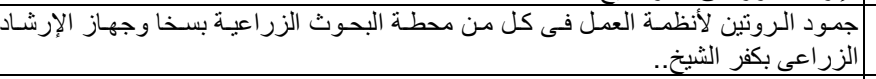 & $\mathrm{v}$ \\
\hline 1.. $\mathrm{V}$ & ITr & 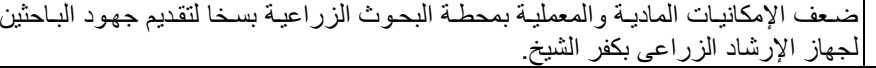 & $\Lambda$ \\
\hline
\end{tabular}




9 | عدم التقاء أهداف كل من محطة البحوث الزر اعبة بسخا وجهاز الإرشاد الزراعى بكفر الثشخ...

رابعا: الأسس التى يجب أن تقوم عليها العلاقة بين محطة البحوث الزراعية بسخا وجهاز الارشـاد الزراعى

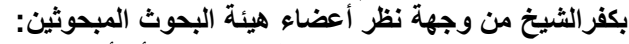

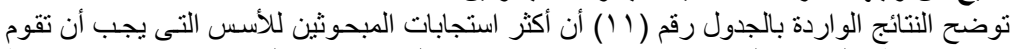

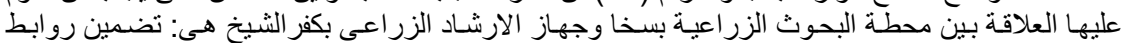

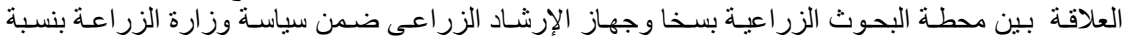

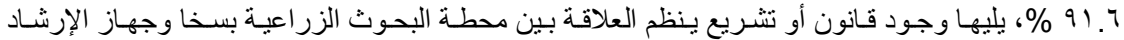

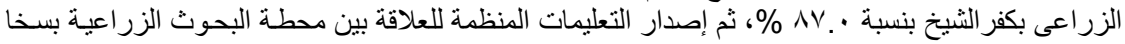

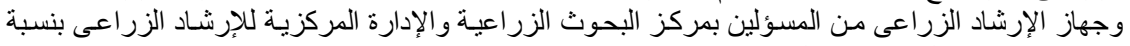

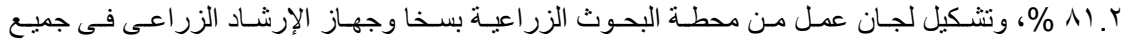

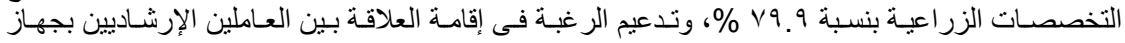

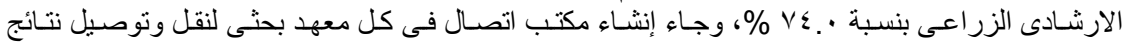

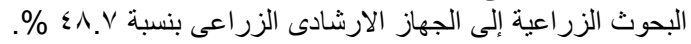

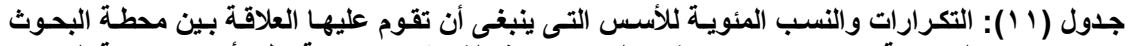

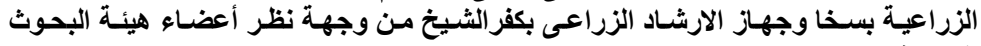

المبحوثين.

\begin{tabular}{|c|c|c|c|}
\hline$\%$ & عدد & 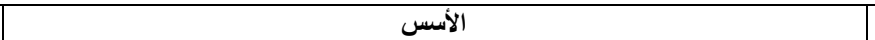 & م \\
\hline$\lambda v_{.} \cdot$ & $1 \pi \xi$ & 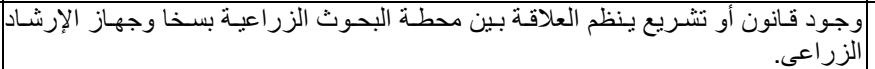 & 1 \\
\hline 91.7 & $1 \leqslant 1$ & |تضياسة وزارة الزراعة. بلعاقة بين محطة البحوث الزراعية بسخا وجهاز الإرشاد الزر اعى.ضمن & $r$ \\
\hline$V \varepsilon$. & $11 \leq$ & تدعيم الرغبة فى إقامة العلاقة بين العاملين الإرشاديين بالجهاز الارشادى الزر اعى. & $r$ \\
\hline 19.9 & TKT & 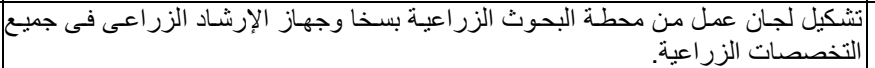 & $\varepsilon$ \\
\hline$\Lambda 1 . r$ & Tro & 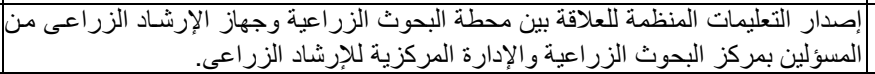 & 0 \\
\hline$\varepsilon \Lambda . V$ & vo & |إنشاء مكتب اتصال فى كل معهد بحثى لنقل وتوصيل نتائج البحوث الزر اعية إلى الجهاز & 7 \\
\hline
\end{tabular}

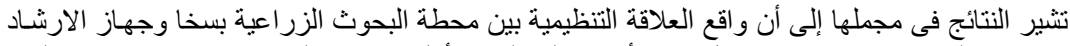

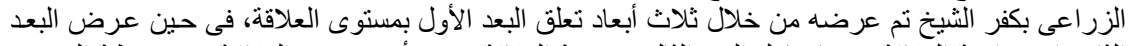

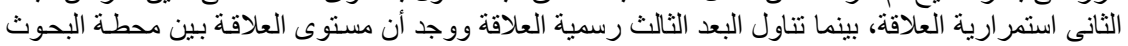

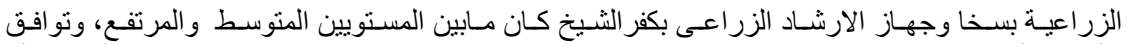

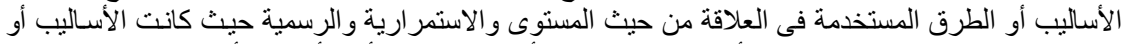

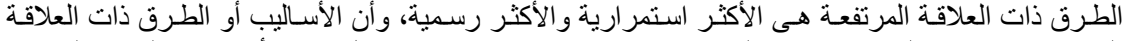

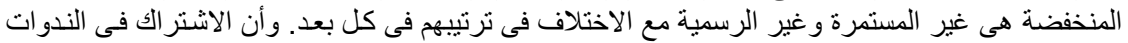

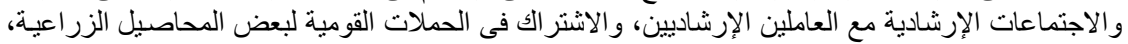

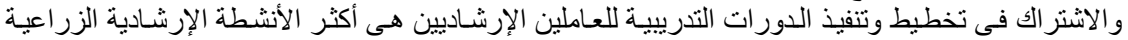

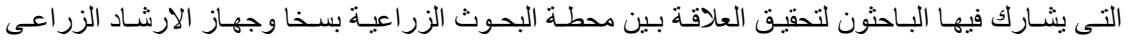


Abdel Wahab, M. M. E. et al.

بكفر الثيخ، بينما كان الاشتر اك فى الإيضـاحات العملية مـع العاملين الإرشـاديين هـى الأقل فى تحقيق العلاقة

كما تبين أن هنالك فروقا معنويـة بين أعضـاء هيئة البحوث المبحوثين الخاصـة بتحديدهم لأبعاد العلاقـة

بينهما.

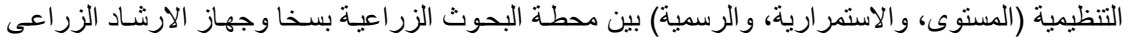

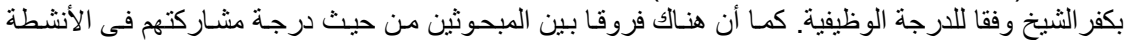

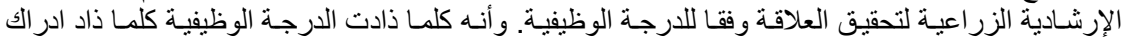

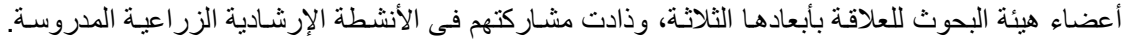

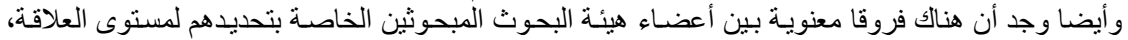

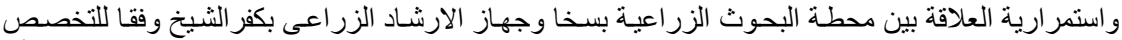

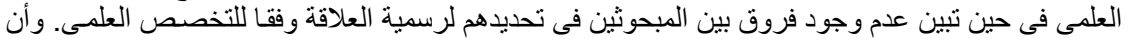

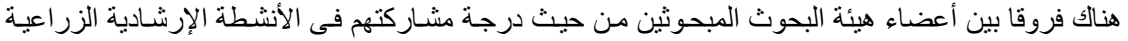

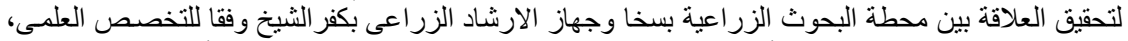

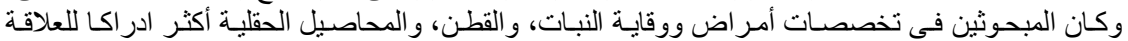

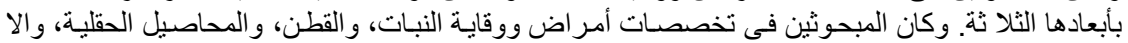

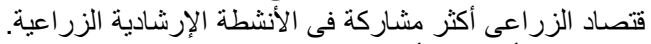

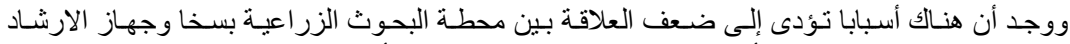

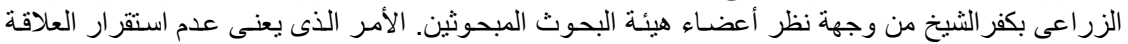

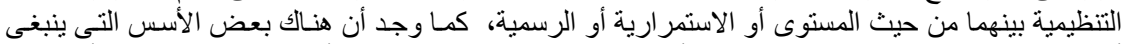

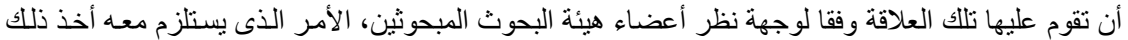

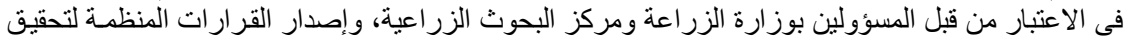

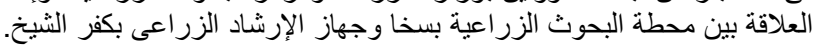

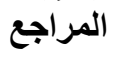

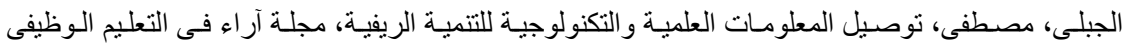

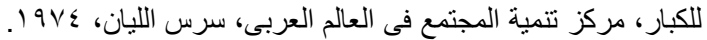

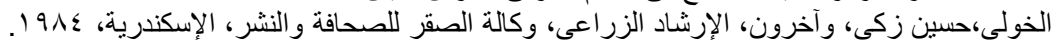

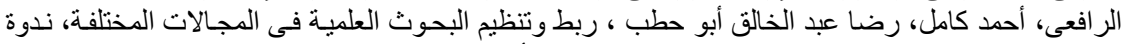

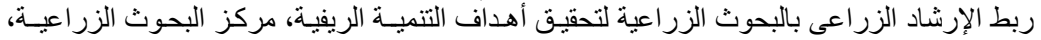

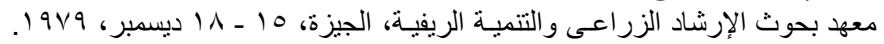

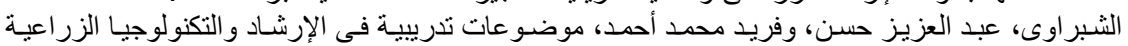

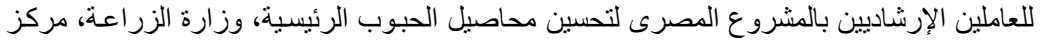

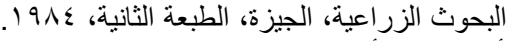

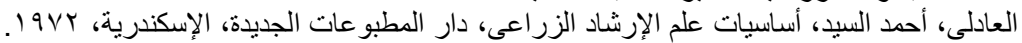

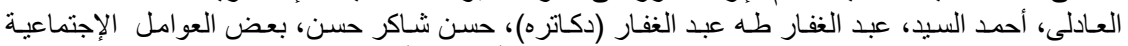

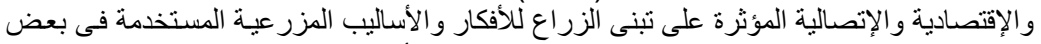

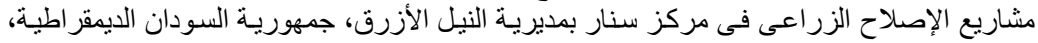

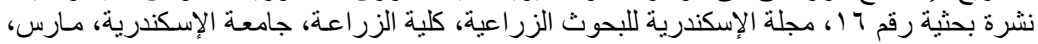
$.19 \vee \varepsilon$

النجار، عطية أحمد محمد، در اسـة لامكانيات تكامل النظـام المعرفى الزر اعى المحلى، رسـالة دكتور اه، كلية

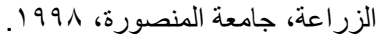

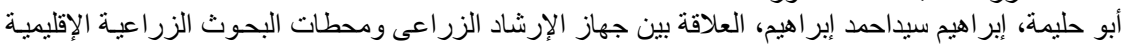

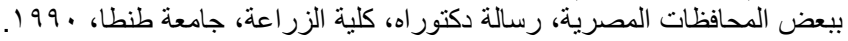

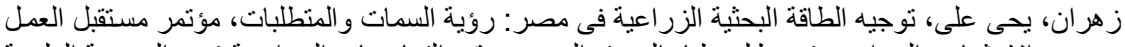

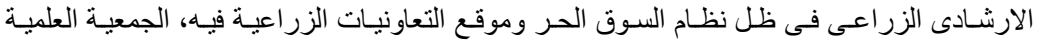

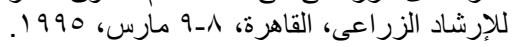

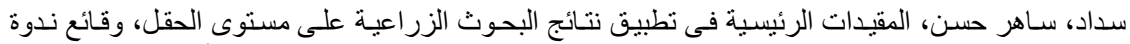

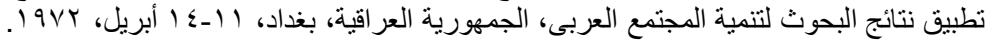




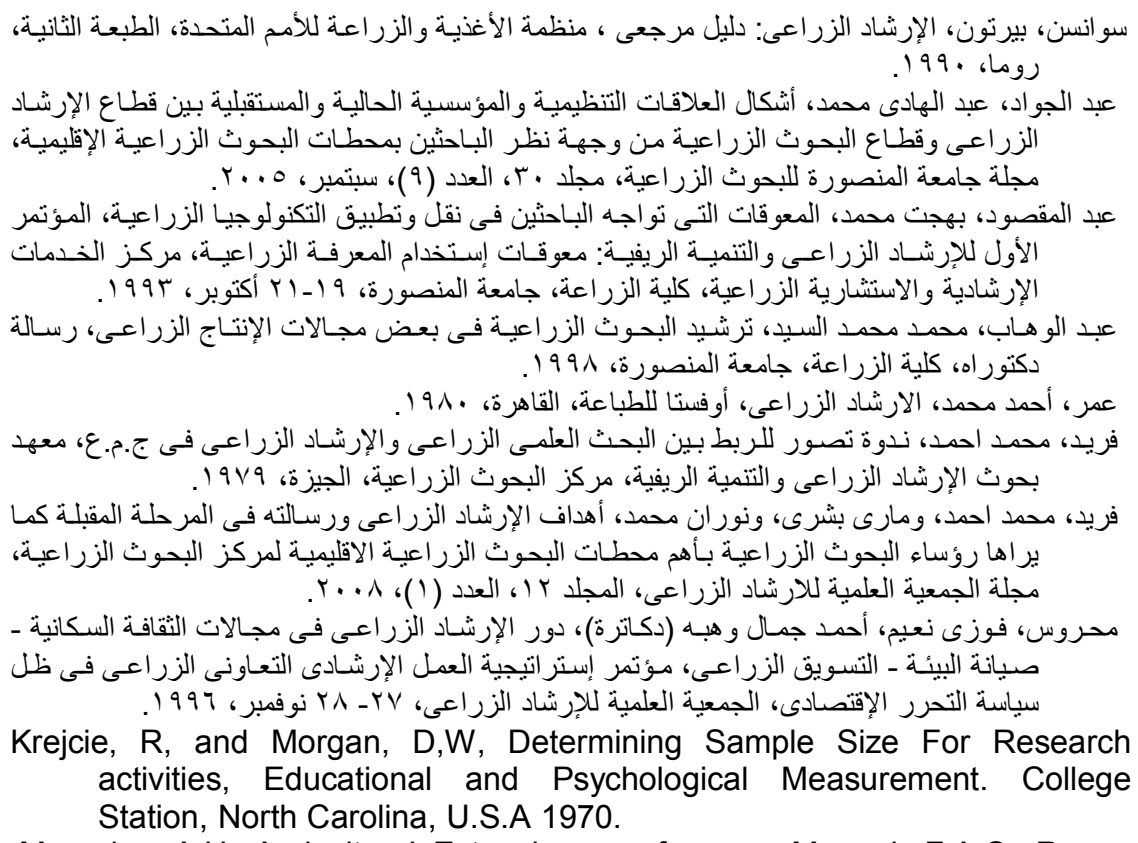

Maunder, A.H, Agricultural Extension a reference, Manual, F.A.O, Rome, 1972.

Niels Roling, Extension Science, New York, New Rochelle, Melbourne Sydney, First Published,1988.

Saches, R.E: Supervision and personal management, $6^{\text {th }}$ Academic seminar for Agricultural Development Experts planning and Extension of Agricultural Extension, Berlin, sep. 4-5 October, 1979.

Swanson, B.E, Agricultural Extension A perchance Manual, 2ed., F.A.O. Rome, 1984.

\title{
ORGANIZATIONAL RELATIONSHIP BETWEEN THE SAKHA AGRICULTURAL RESEARCH STATION AND THE AGRICULTURAL EXTENSION ORGANIZATION IN KAFR EL- SHEIKH GOVERNORATE FROM THE VIEWPOINT OF THE MEMBERS OF THE RESEARCH.
}

Abdel Wahab, M. M. EL; J. I. Issawi and A. A. Ismail Research Institute of Agricultural Extension and Rural Development Agricultural Research Center.

\begin{abstract}
This research aimed mainly at identifying the organizational relationship between the Sakha Agricultural Research Station and the Agricultural Extension Organization in Kafr El-Sheikh Governorate regarding:
\end{abstract}


level, continuity, official., identify differences of the relationship among respondents in participation, identifying the participation researchers in agricultural extension activities, differences among respondents in participation in extension activities, recognizing the causes that lead to the weakness of the relationship, and recognizing the principles which should underlie the relationship. The study was conducted at in the Sakha Agricultural Research Station, Data were collected through personal interview questionnaire from a random simple of 154 respondents representing about $60 \%$ of the total number of researchers. "f" test, the Arithmetic means, standard deviation, frequencies, percentages were used to analyze data. The main findings are as follows:

The relationship between the Sakha Agricultural Research Station and the Agricultural Extension Organization in Kafr El-Sheikh Governorate was medium and high $59.1 \%, 28.6 \%$, respectively.

Similar results were obtained with regard to continuity and formality. The most common item are :field and harvesting days, demonstration fields, national campaigns, and training courses for extension workers, where as the less common item are office visits, planning and implementation of supportuy experiments in the fields of farmers, and training for subject matter specialists according to their specialization.

- Participation in symposium and extension meetings with extension workers, participation in national campaigns for some agricultural crops, and participation in planning and implementing training courses for extension workers are the meet, attended by researchers to achieve the relationship between the Sakha Agricultural Research Station and the Agricultural Extension Organization in Kafr El-Sheikh Governorate, while participation in the demonstration fields with the Extension workers are the lowest in the relationship between them.

- There are differences in perception of the dimensions of the relationship (level, continuity, official) between the Sakha Agricultural Research Station and the Agricultural Extension Organization in Kafr El-Sheikh Governorate according to professional position and specialty with regard to strength and continuity of the relationship.

- There are differences according to professional faction only with respect to formality.

- The findings showed some causes that lead to the weakness of the relationship between the Sakha Agricultural Research Station and the Agricultural Extension Organization in Kafr El-Sheikh Governorate, and principles which should underlie the relationship.

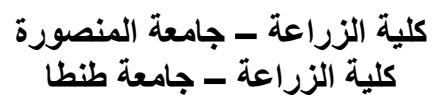

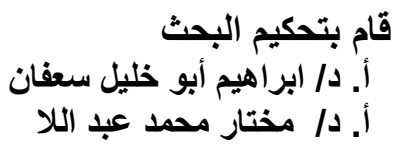

